\title{
Dynamic polymer systems with self-regulated secretion for the control of surface properties and material healing
}

\section{Citation}

Cui, Jiaxi, Daniel Daniel, Alison Grinthal, Kaixiang Lin, and Joanna Aizenberg. 2015. Dynamic polymer systems with self-regulated secretion for the control of surface properties and material healing. Nature Materials 14: 790-795. doi:10.1038/nmat4325

\section{Published Version}

doi:10.1038/nmat4325

\section{Permanent link}

http://nrs.harvard.edu/urn-3:HUL.InstRepos:27657491

\section{Terms of Use}

This article was downloaded from Harvard University's DASH repository, and is made available under the terms and conditions applicable to Other Posted Material, as set forth at http:// nrs.harvard.edu/urn-3:HUL.InstRepos:dash.current.terms-of-use\#LAA

\section{Share Your Story}

The Harvard community has made this article openly available.

Please share how this access benefits you. Submit a story.

\section{Accessibility}


Dynamic polymer systems with self-regulated secretion for the control of surface properties and material healing

Jiaxi Cui, ${ }^{1,2}$ Daniel Daniel, ${ }^{1}$ Alison Grinthal, ${ }^{1}$ Kaixiang Lin,${ }^{3}$ and Joanna Aizenberg ${ }^{1,2,3,4}$ *

${ }^{1}$ School of Engineering and Applied Sciences, Harvard University, Cambridge, MA 02138, USA; ${ }^{2}$ Wyss Institute for Biologically Inspired Engineering, Harvard University, Cambridge, MA 02138, USA; ${ }^{3}$ Department of Chemistry and Chemical Biology, Harvard University, Cambridge, MA 02138, USA; ${ }^{4}$ Kavli Institute for Bionano Science and Technology, Harvard University, Cambridge, MA 02138, USA.

*To whom correspondence should be addressed. Email: jaiz@seas.harvard.edu

Approaches for regulated fluid secretion, which typically rely on fluid encapsulation and release from a shelled compartment, do not usually allow for a fine, continuous modulation of secretion, and can be difficult to adapt for monitoring or functionintegration purposes. ${ }^{1-5}$ Here, we report self-regulated, self-reporting secretion systems consisting of liquid-storage compartments in a supramolecular polymer-gel matrix with a thin liquid layer on top, and demonstrate that dynamic liquid exchange between the compartments, matrix and surface layer allows for repeated, responsive self-lubrication of the surface layer and for cooperative healing of the matrix. Depletion of the surface liquid or local material damage induces self-regulated secretion of the stored liquid via a dynamic feedback between polymer crosslinking, droplet shrinkage and liquid transport that can be read out through changes in the system's optical transparency. We envision diverse applications in fluid delivery, wetting and adhesion control, and material self-repair.

Nearly every form of living tissue autonomously packages, transports, and secretes fluids, mediating defense, adhesion, wound healing, temperature - often several of these at once - through tightly self-regulated release systems. ${ }^{6-9}$ Fundamental to these systems, fluid storage is itself an active, finely regulated balance. Storage droplets or vesicles continuously adjust their size, shape and contents through ongoing exchange with the surroundings, creating intrinsically responsive control mechanisms that tie secretion to a wide range of chemical and physical stimuli and feedback signals. ${ }^{10-13}$ At the same time, collective changes in the stores are reported to the organism, alerting it that it needs to drink or eat to replenish the limited supply. Many synthetic approaches have been developed to enable triggered release from microcapsules, hydrogels, nanoparticles, vesicles, micelles, mesoporous carriers and other containers. ${ }^{1-5,14-17}$ While these systems can secrete fluid in response to various stimuli, it remains a challenge to design a synthetic approach that displays finely tuned, continuous self-adjustment, integrated functionalities, and continuous liquid supply monitoring. 


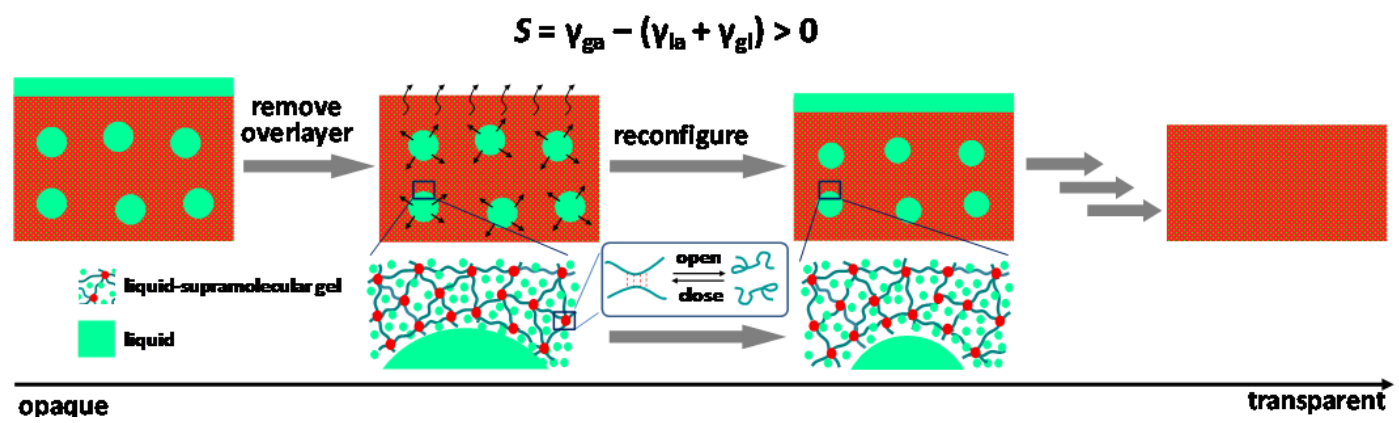

Figure 1. Schematic of the self-regulated, liquid secretion system. Secretion liquid is stored as shell-less droplets inside a gel matrix composed of dynamic polymers, with ongoing liquid exchange between droplet and gel phases. If $S=\gamma_{\mathrm{ga}}-\left(\gamma_{\mathrm{la}}+\gamma_{\mathrm{gl}}\right)>0$, the matrix surface will be coated with a thin liquid overlayer. When this layer is removed, the disjoining pressure will trigger secretion of the stored liquid to restore the original film thickness, while the supramolecular gel matrix reconfigures through reversible bond disassembly and reassembly to release any buildup of mechanical stress due to shrinking droplets. With successive removal/restoring cycles, the liquid droplets will continuously shrink and the gel will become progressively transparent.

Inspired by living systems, we present a strategy for designing self-forming, continuously self-regulating secretion systems that are able to maintain a constant thin liquid coating, self-heal, and self-report their liquid content. Rather than relying on separately constructed storage particles, our concept is based on packaging the liquid as discrete, shellless storage droplets inside a polymer gel matrix (Fig. 1), with a continuous, dynamic liquid exchange between the droplets, matrix, and surface. The droplet-gel interface will be associated with an intrinsic energy penalty, $E_{A}=n A \gamma_{\mathrm{gl}}$, where $n, A$, and $\gamma_{\mathrm{gl}}$ are the number, area and interfacial energy of the droplets (see Supplementary Information section 1.1, Fig. S1 for detailed discussion), ${ }^{18}$ such that it will generally be thermodynamically favorable for the droplets to decrease their surface area. However, there will be a kinetic barrier to doing so, due to the associated polymer bond reorganization. Hence, the system will be metastable, if the matrix crosslinking bonds are strong enough to immobilize and stabilize the droplets, more precisely if $E_{\text {bond }} \gtrsim 10 K_{B} T$, where $K_{B}$ is Boltzmann constant and $T$ is the gel temperature. At the same time, the gel outer surface will be coated with a stable liquid film as long as the spreading factor $S=\gamma_{\mathrm{ga}}-\left(\gamma_{\mathrm{la}}+\gamma_{\mathrm{gl}}\right)>0$, where $\gamma_{\mathrm{ga}}, \gamma_{\mathrm{la}}$ and $\gamma_{\mathrm{gl}}$ are the gel-air, liquid-air, gel-liquid interfacial tensions, respectively (see Supplementary Information section 1.2, Fig. S2 for detailed discussion). ${ }^{19}$ The thickness of the liquid film on the gel surface is determined by the disjoining pressure and typically ranges from tens to hundreds of nanometers. If this layer is disturbed or removed, the disjoining pressure will create a driving force to restore the original thickness. Even though the origin of the disjoining pressure is van der Waals interactions at the gel surface, the pressure can act on the droplets in the bulk matrix, because of liquid continuity. If $E_{\text {bond }}$ is on the order of $10 K_{B} T$ or less, the pressure 
will be sufficient to induce secretion from the stored droplets, with bond reorganization preventing any build-up of mechanical stress as the droplets shrink. The decrease in droplet size will also reduce the amount of light scattering in the bulk material so that the gel becomes progressively transparent as the stores diminish, providing a convenient, ongoing readout.

Creating a system with these properties requires 1) a polymer with chemical affinity to the stored liquid and bonding strength both strong enough to stabilize the droplets and weak enough to allow bond reconfiguration and hence inducible secretion, and 2) a formation mechanism that leads to kinetically trapped droplets to begin with. The first requirement can be met with supramolecular polymers. Here we design copolymers of urea and polydimethysiloxane (uPDMS), which reversibly crosslink via hydrogen-bonding of the urea units. $^{20,21}$ The synthetic details and polymer characterization by NMR, FT-IR, gel permeation chromatography (GPC), thermogravimetric analysis (TGA), differential scanning calorimetry (DSC), UV-Vis spectrometry and mechanical testing are provided in Supplementary Information sections 2 and 3.1, Figs. S3-S9, Table S1). Differences in the spacer units ( $R$ in Fig. 2a) result in different crosslinking strengths (uPDMS $2>\mathrm{uPDMS}_{1}$; Fig. S6), but in each case $E_{\text {bond }} \approx 7 K_{B} T$ or $16 \mathrm{~kJ} / \mathrm{mol}^{22}$ The second requirement can be met through phase separation. ${ }^{23,24}$ If the polymer is dissolved along with an excess of secretion liquid in a volatile solvent (in our case silicone oil and tetrahydrofuran (THF), respectively), rapid evaporation of the solvent can then be expected to trigger crosslinking of the polymer, trapping some of the secretion liquid within the polymer network while leaving the excess to form droplets within the matrix.

With this strategy, a droplet-embedded material self-forms in a single synthetic step through a highly concerted process. When a homogeneous solution of uPDMS, silicone oil, and THF was coated on a glass substrate, THF evaporation initially led to high polymer concentration and gelation at the liquid-air interface to form a relatively droplet-free layer (Fig. 2a i and ii). ${ }^{25,26}$ With continued evaporation, uPDMS began to crosslink inside the bulk film, accompanied by phase separation: micron-scale oil droplets first began to nucleate inside the bulk solution and grew by fusing with each other to reduce the energy penalty $E_{A}$ discussed above. Ultimately, gelation occurred throughout the bulk film, immobilizing the oil droplets and stopping any further fusion (Fig. 2a iii; discussion in SI). The final size and distribution of the droplets thus depend on the dynamics of the phase separation and gelation processes, with faster gelation leaving less time for droplets to fuse and grow before becoming trapped (Fig. 2a ii and iii, and Fig. S7). 
a
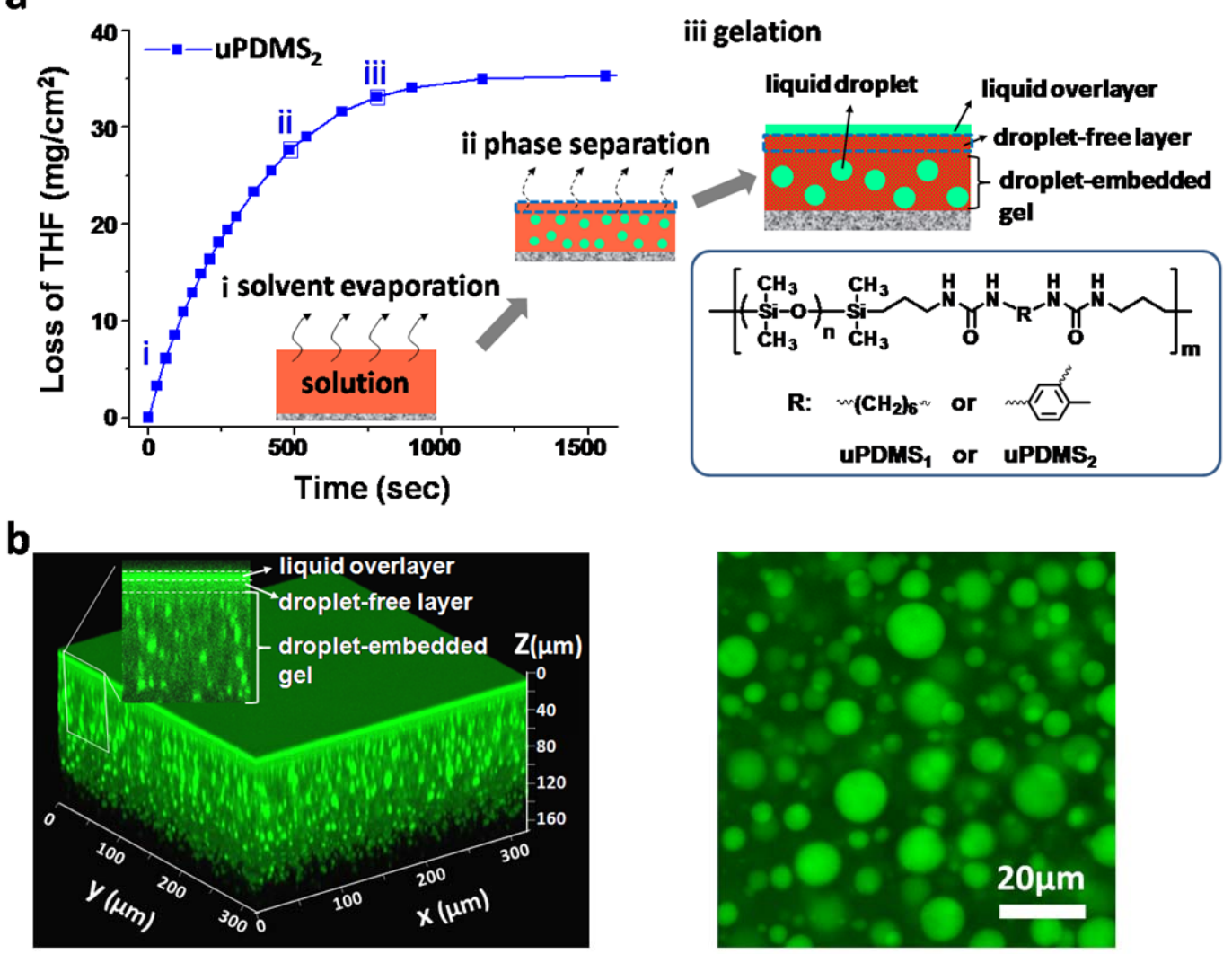

c
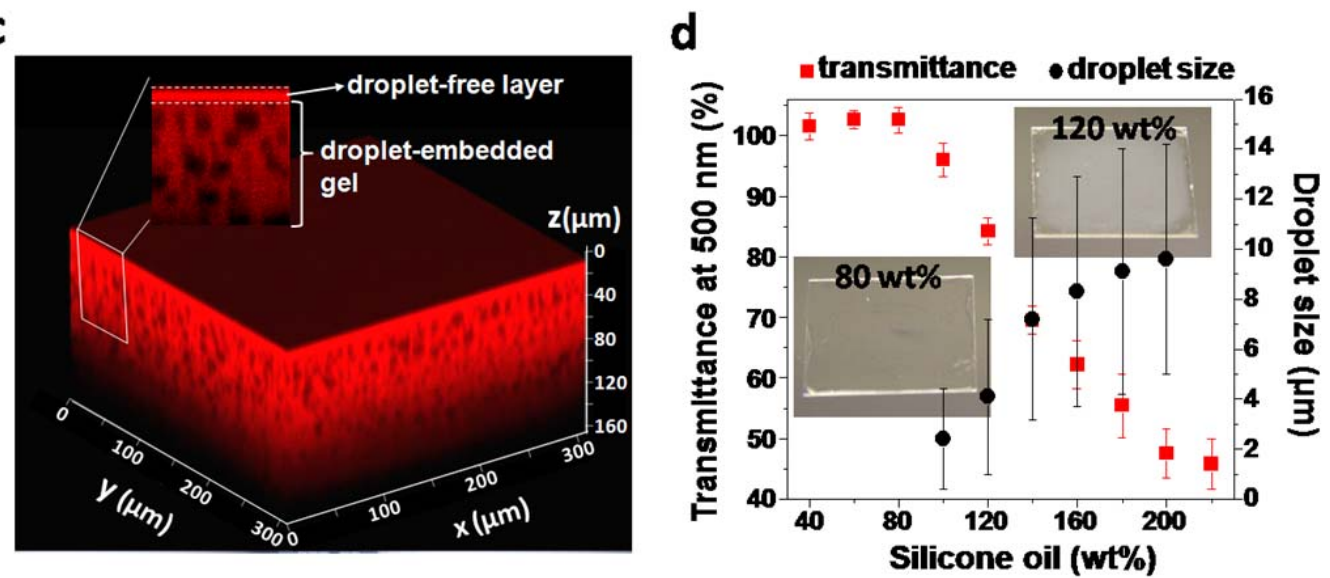

Figure 2. Characterization of droplet-embedded gel structure. a, THF evaporation in a solution of $\mathrm{uPDMS}_{2}$ polymer, silicone oil, and THF, and corresponding schematic of the self-formation of droplet-embedded gel film: i) homogeneous solution; ii) phase separation; iii) isolated liquid droplets trapped within hydrogen-bonded crosslinked gel. $\mathbf{b}$, Confocal fluorescence image of $\mathrm{uPDMS}_{2}$-based film, using PDI-conjugated silicone oil to visualize the liquid (3D image on left and horizontal crosssection on right). c, 3D confocal fluorescence image of $\mathrm{uPDMS}_{2}$-based film, using PDI-conjugated $\mathrm{uPDMS}_{2}$ to visualize the polymer. Silicone oil loading $\left(\mathrm{W}_{\text {oil }} / \mathrm{W}_{\text {copolymer }}\right)$ of $160 \mathrm{wt} \%$ was used in a-c. d, Transmittance at $500 \mathrm{~nm}$ wavelength and the average size of the individual liquid droplets with different silicone oil loadings. The films do not show any absorption at $500 \mathrm{~nm}$ (see Fig. S9 for details). Transmittance data were obtained from eight independent measurements of gel films with thicknesses of $200 \pm 20 \mu \mathrm{m}$ while size values were estimated from 100 droplets selected randomly (see Fig. S10 for measurement details). Error bars are s.e.m. 
Complementary confocal imaging of the liquid and polymer confirm that this process generates a droplet-embedded gel matrix with a thin liquid layer on top. To enable imaging and detailed structure investigation, we conjugated the fluorescence marker perylenediimide (PDI) either to the silicone oil or to the polymer (see Supplementary Information sections 3.2-3.3 for synthesis, Fig. S4 and S8). As described here for $\mathrm{uPDMS}_{2}$ as an example, above a threshold loading ( $80 \mathrm{wt} \%$ ), discrete microscale droplets of pure liquid, observed as bright spots and corresponding dark holes in the liquid- and polymer-labeled images respectively, are dispersed throughout a polymer-liquid matrix (Fig. $2 b$ and c). The liquid layer on the surface is clearly seen in Fig. 2b, but absent from the inverse polymer image in Fig. 2c. The thickness of this overlayer is $\sim 200 \mathrm{~nm}$ (not resolvable using confocal microscopy, hence estimated by mass; see Supplementary Information section 4.5), consistent with expectations based on disjoining pressure. A less intense liquid-containing region just below, but distinct from, this overlayer, corresponding to a thin bright, relatively droplet-free polymer region, is consistent with the surface polymer concentration and gelation observed at the initial stage of solvent evaporation. The droplet size and density increase with increasing oil content while remaining in the microscale range, leading to increasing light scattering and a progressive decrease in transmission (Fig. 2d and Fig. S9).

Undisturbed, the liquid layer thickness (500 and $200 \mathrm{~nm}$ for $\mathrm{uPDMS}_{1}$ and $\mathrm{uPDMS}_{2}$, respectively) and the droplet size distribution remain constant for at least two weeks. Removing the liquid overlayer triggers secretion of the stored liquid to the exposed surface until the original thickness is restored, as seen by the reduction and subsequent recovery of fluorescence intensity at the surface (Fig. 3a). Full recovery takes about $30 \mathrm{~h}$ for $\mathrm{uPDMS}_{2}$ (monitored by mass, Fig. 3b and Supplementary Information section 4.5) but only $4 \mathrm{~h}$ for $\mathrm{uPDMS}_{1}$ where the crosslinking strength is weaker (Fig. S6), implying that the bond reorganization is the time-limiting step to secretion. This surface-triggered secretion is accompanied by a decrease in droplet size. Over 60 cycles of surface liquid removal/restoration, droplet size (Fig. S10) progressively decreases throughout the whole matrix, albeit at different rates. Droplets closest to the surface initially shrink most, while those furthest shrink least (Fig. 3c and Fig. S11). The droplet shrinkage is accompanied with decreasing light scattering and increasing transmission (Fig. 3d and Fig. S12). This correlation provides a self-reporting feature that allows us to track consumption of the storage droplets continuously throughout multiple rounds of secretion. Full transparency associated with complete consumption of droplets further correlates with loss of secretion ability, not only supporting optical transmission as a readout of functional capacity but also indicating 
that the droplets, and not the liquid that is homogeneously distributed within the polymer matrix, are essential to secretion. Since $\mathrm{uPDMS}_{1}$ secretes more liquid per cycle than $\mathrm{uPDMS}_{2}, \mathrm{uPDMS}_{1}$ becomes transparent and loses its secreting ability in fewer cycles.

a

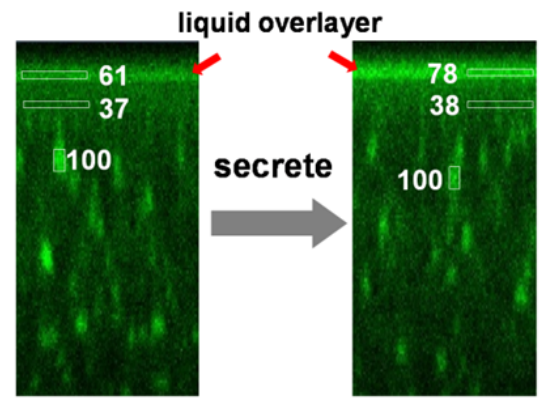

C

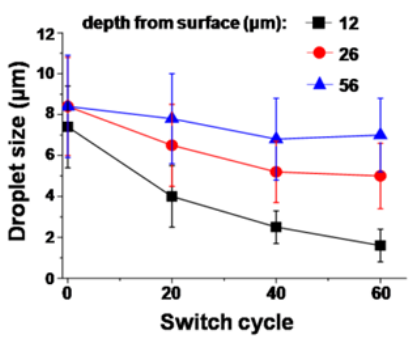

d

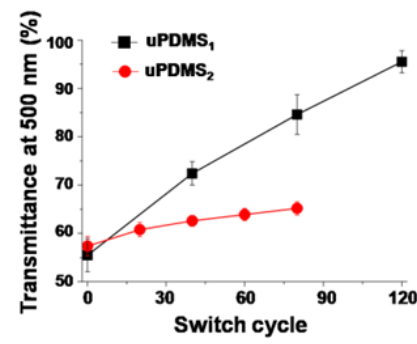

b

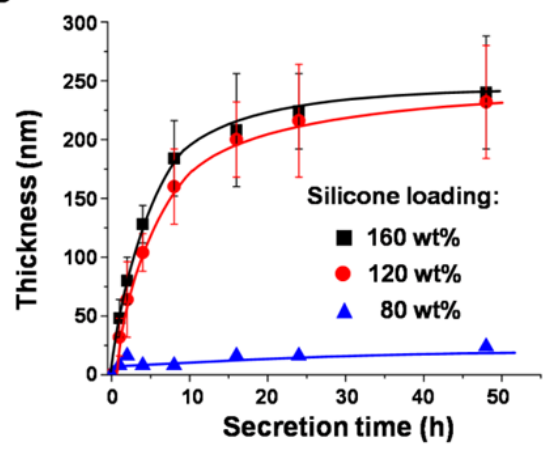

e

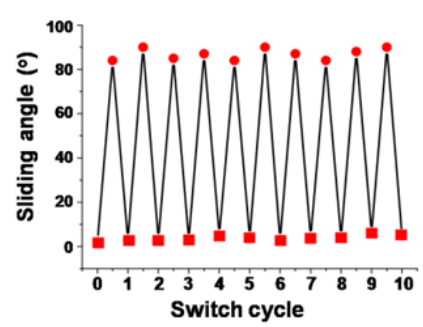

Figure 3. Self-regulated secretion by the droplet-embedded gel films. a, Vertical cross-section fluorescence images of $\mathrm{uPDMS}_{2}$-based film containing PDI-conjugated silicone oil after removing the liquid coating (left) and $30 \mathrm{~h}$ later (right). Numbers show normalized fluorescence intensity. $\mathbf{b}$, Secretion kinetics for films with different silicone oil loadings. A transparent sample with a loading of $80 \mathrm{wt} \%$ was used as control. The thickness of the silicone oil overlayer was estimated by mass (see SI section 4.5 for details). Error bars are s.e.m. from 3 samples. c, Liquid droplet sizes at different depths $v s$ the number of removal-restoring cycles. Error bars are s.e.m from 100 droplets. d, Transmittance changes of both $\mathrm{uPDMS}_{1}$ - and $\mathrm{uPDMS}_{2}$-based films $v s$ the number of cycles. Error bars are s.e.m. from 8 samples. e, Water sliding angle during cycles of liquid surface layer removal (circles) and restoring (squares). Typical time between removal and restoring measurements was $30 \mathrm{~h}$. The samples used in a, c, d, and e contained $160 \mathrm{wt} \%$ silicone oil and have thicknesses of $200 \pm 20 \mu \mathrm{m}$.

This secretion process creates and repeatedly restores a highly slippery, foulingresistant surface. ${ }^{27,28}$ A $10 \mu \mathrm{L}$ water droplet slides off the initial liquid-coated surface at a low tilt angle of $<5^{\circ}$, while the sliding angle increases to $\sim 90^{\circ}$ following removal of the liquid layer. The sliding angle consistently returns to $<5^{\circ}$ following triggered secretion, over at least 10 cycles of surface liquid removal/restoration (Fig. 3e), indicating that the secretion process recovers a smooth, homogeneous outer layer. Such secretion-driven, continuous selflubrication of the polymer film exposed to a flow cell results in the retention of the wetting and non-adhesive properties of the material until the entire reservoir of the stored liquid is depleted (Fig. S13). 
The interplay between liquid secretion and polymer bond reorganization is not only important in the surface-secretion process described above, but also plays a crucial role in the gel's self-healing ability. Fig. 4a shows the schematic of the self-healing process when the polymer network is damaged locally, for example when cut with a knife (Movie 1). Liquid droplets ruptured along the cut surface can release enough silicone oil to form a $\sim 1 \mu \mathrm{m}$ thick film (based on typical droplet size and number density) over the newly exposed surface, but not enough to fill the crevice created, which can be as large as $20 \mu \mathrm{m}$ wide (Fig. S14). Mechanical pressure due to the cutting action is able to cause enough secretion of liquid from neighboring droplets not immediately along the cut surface to fill the crevice (Fig. S15). Surface tension then drives the redistribution of the secreted silicone oil to form a uniform film (Fig. 4a ii), within a minute for $160 \mathrm{wt} \% \mathrm{uPDMS}_{2}$ (Fig. 4b).

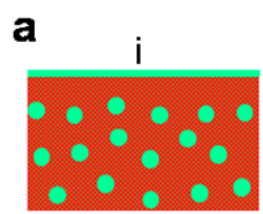

b
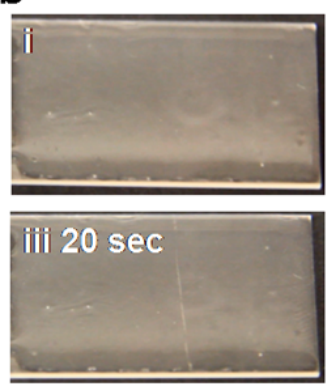

d
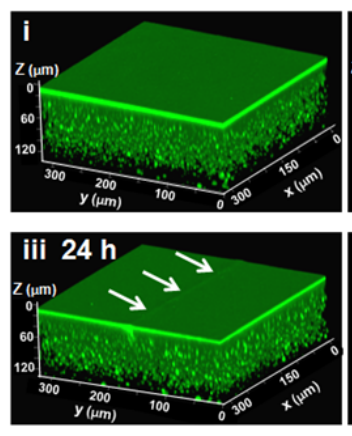
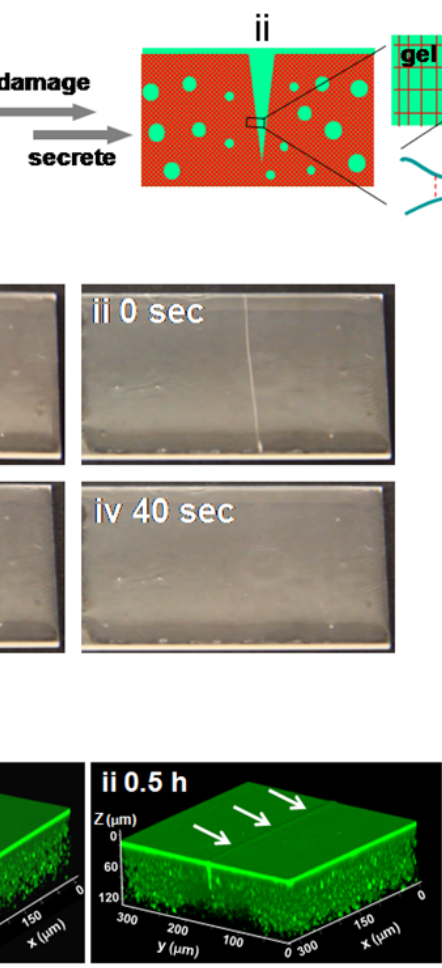

iv $72 \mathrm{~h}$

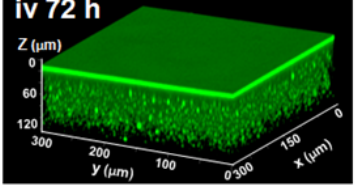

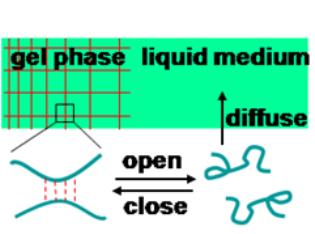

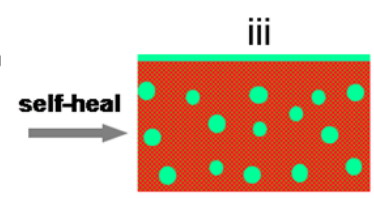

C

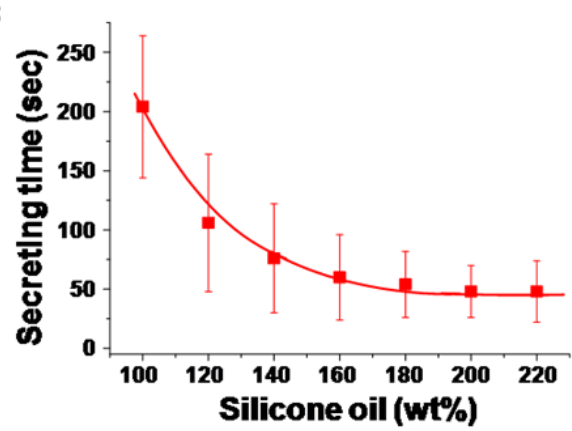

e

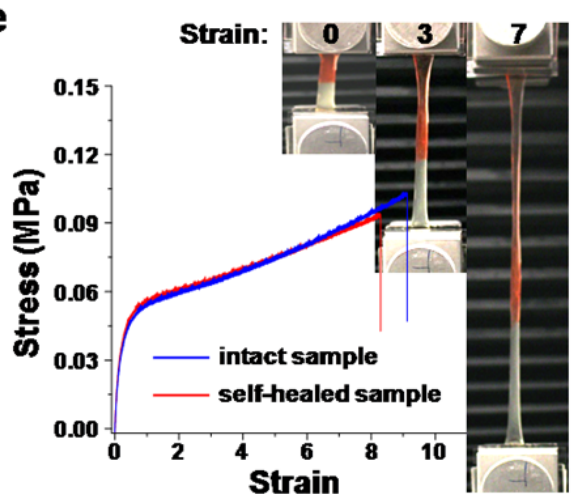

Figure 4. Self-healing of droplet-embedded gel materials. a, Schematic model of secretionmediated response to polymer damage. $\mathbf{b}$, Optical images of $\mathrm{uPDMS}_{2}$-based film before damage (i) and after damage at $0 \mathrm{~s}$ (ii), $20 \mathrm{~s}$ (iii), and $40 \mathrm{~s}$ (iv). c, Secreting time for filling the void, for different loadings of silicone oil. Error bars are s.e.m. from 6 samples. d, 3D confocal fluorescence images before damage (i) and after damage at $0.5 \mathrm{~h}$ (ii), $24 \mathrm{~h}$ (iii), and $72 \mathrm{~h}$ (iv). Arrows highlight the damaged region (note the scar of the secreted liquid on the surface along the cut). The polymer films have thicknesses of $200 \pm 20 \mu \mathrm{m}$ in a-c. e, Stress-strain curves of the intact and self-healed $\mathrm{uPDMS}_{2}$ - 
based sample. Inset images show the self-healed sample composed of two pieces under different strains (one piece was dyed in red for contrast). The silicone oil loading was $160 \mathrm{wt} \%$ in a, c, d, and e.

This time increases with decreasing liquid loading (Fig. 4c), but is still much shorter than the time required to restore the outer surface liquid overlayer in the absence of damage, likely because liquid redistribution does not require matrix reconfiguration, which occurs much later, and is rather associated with the rupture of oil droplets directly in the damaged area and damage-induced pressure and liquid flow from the nearest droplets. Over the next 72 $\mathrm{h}$ the bonds within the supramolecular polymer network itself disassemble and reassemble, zipping from the bottom to the top of the liquid-filled crevice until the damage disappears completely (Fig. 4d ii-iv and Fig. S14). A self-healing efficiency of $88 \%$ (defined as proportion of toughness restored relative to the original value) was obtained from tensile measurements of uPDMS 2 with $160 \mathrm{wt} \%$ silicone oil loading (Fig. 4e). In the present system, we propose that the rapid secretion of liquid into the void promotes self-healing by providing a medium for polymer diffusion to enable spontaneous polymer reassembly (Fig. 4a ii-iii). This explains why self-healing starts from the bottom, where the crevice width (hence the polymer's diffusion length) is at its minimum. In the absence of this liquid region, e.g. for pure supramolecular polymer film with no droplets, self-healing can still occur, but requires higher temperature or significantly more time at room temperature, $>2$ weeks, with the selfhealing efficiency of $\sim 50 \%$ (Fig. S16).

Besides polymeric films and coatings, this strategy can be used to create analogous systems with a wide range of morphologies, such as fibers and microbeads (Supplementary Information section 4.10, Fig. S17). In addition, we have prepared uPDMS gels using other liquids such as mineral and plant oil, and observed similar structures and release behaviors (Supplementary Information section 4.11, Fig. S18), indicating a general strategy for preparing self-regulation secretion systems.

By designing liquid storage compartments to be part of a system-wide dynamic liquid exchange with the matrix and surface, we have introduced a platform for developing a variety of self-adjusting, self-reporting secretion materials. The intrinsic feedback mechanism governing the behavior of the system creates opportunities for tuning the secretion kinetics over a broad range, by controlling factors such as (i) the crosslinking density of the polymer backbone, (ii) the type and strength of the reversible supramolecular polymer bonds (hydrogen bonding, stacking, etc., (iii) the chemical and physical properties of the stored liquid, and (iv) the kinetics and conditions of the formation reaction, which control the structure of the surface layer, matrix, and size of the stored droplets. This fine tunability in 
turn enables, for example, surface re-lubrication kinetics to be tailored for antifouling and other uses in a variety of environments where the liquid overlayer may be subjected to different shear, evaporation, or even biological colonization rates. The general principles underlying formation and function can be applied to a wide range of morphologies, materials, and secretion liquids, suggesting potential applications in repairing material damage and tailoring material surface properties such as wetting, slipperiness, adhesion, and fouling resistance, as well as in drug delivery, agriculture, heat transfer, and modulation of local $\mathrm{pH}$, humidity, and other conditions.

\section{Acknowledgements}

The work was supported by the DoE under award \# DE-SC0005247 (polymer synthesis and selfrepair) and ARPA-E under the award \# DE-AR0000326 (wetting and anti-fouling properties). We thank Mr. Jack Alvarenga for his help with the flow-cell design and measurements and Dr. Y. Hu and Dr. M. Aizenberg for discussion.

\section{Author contributions}

J.C. and J.A. conceived the concepts of the research. J.A. supervised the research. J.C. designed and performed the experiments. D.D. did theoretical analysis and calculation; K.L. conducted secretion experiment with mineral and plant oil; A.G., J.C. and J.A. analyzed the results; J.C., D.D., A.G., and J.A. wrote the manuscript.

\section{Additional information}

Supplementary information is available in the online version of the paper. Reprints and permissions information is available online atwww.nature.com/reprints. Correspondence and requests for materials should be addressed to J.A.

\section{Competing financial interests}

The authors declare no competing financial interests.

\section{References}

1 Tokarev, I. \& Minko, S. Stimuli-responsive porous hydrogels at interfaces for molecular filtration, separation, controlled release, and gating in capsules and membranes. Adv. Mater. 22, 3446-3462 (2010).

2 Esser-Kahn, A. P., Odom, S. A., Sottos, N. R., White, S. R. \& Moore, J. S. Triggered release from polymer capsules. Macromolecules 44, 5539-5553 (2011).

3 Timko, B. P., Whitehead, K., Gao, W., Kohane, D. S., Farokhzad, O., Anderson, D. \& Langer, R. Advances in drug delivery. Annu. Rev. Mater. Res. 41, 1-20 (2011).

4 Mura, S., Nicolas, J. \& Couvreur, P. Stimuli-responsive nanocarriers for drug delivery. Nat. Mater. 12, 991-1003 (2013).

5 van Dongen, S. F. M., de Hoog, H.-P. M., Peters, R. J. R. W., Nallani, M., Nolte, R. J. M. \& van Hest, J. C. M. Biohybrid Polymer Capsules. Chem. Rev. 109, 6212-6274 (2009).

6 Miyake, K., Tanaka, T., \& McNeil, P. L. Disruption-induced mucus secretion: repair and protection. PLoS Biol. 4, e276 (2006).

7 Shibasaki, M., Wilson, T. E. \& Crandall, C. G. Neural control and mechanisms of eccrine sweating during heat stress and exercise. J. Appl. Physiol. 100, 1692-1701 (2006).

8 Thiam, A. R., Farese, R. V., Jr. \& Walther, T. C. The biophysics and cell biology of lipid droplets. Nat. Rev. Mol. Cell Biol. 14, 775-786 (2013). 
9 Andreeva, A. V., Kutuzov, M. A. \& Voyno-Yasenetkaya, T. A. Regulation of surfactant secretion in alveolar type II cells. Am. J. Physiol. Lung Cell Mol. Physiol. 293, L259-L271 (2007).

10 Jeanrenaud, B. \& Rohner-Jeanrenaud, F. Effects of neuropeptides and leptin on nutrient partitioning: dysregulations in obesity. Annu. Rev. Med. 52, 339-351 (2001).

11 Ashcroft, F. M. \& Rorsman, P. KATP channels and islet hormone secretion: new insights and controversies. Nat. Rev. Endocrinol. 9, 660-669 (2013).

12 Miyake, K., Tanaka, T. \& McNeil, P. L. Disruption-induced mucus secretion: repair and protection. PLoS Biol 4, e276 (2006).

13 Gustafsson, J. K., Navabi, N., Rodriguez-Pineiro, A. M., Alomran, A. H. A., Premaratne, P., Fernandez, H. R., Banerjee, D., Sjovall, H., Hansson, G. C. \& Linden, S. K. Dynamic changes in mucus thickness and ion secretion during citrobacter rodentium infection and clearance. PLoS One 8, e84430 (2013).

14 Delcea, M., Moehwald, H. \& Skirtach, A. G. Stimuli-responsive LbL capsules and nanoshells for drug delivery. Adv. Drug Delivery Rev. 63, 730-747 (2011).

15 Liechty, W. B., Kryscio, D. R., Slaughter, B. V. \& Peppas, N. A. Polymers for drug delivery systems. Annu. Rev. Chem. Biomol. Eng. 1, 149-173 (2010).

16 Trewyn, B. G., Slowing, I. I., Giri, S., Chen, H.-T. \& Lin, V. S. Y. Synthesis and functionalization of a mesoporous silica nanoparticle based on the sol-gel process and applications in controlled release. Acc. Chem. Res. 40, 846-853 (2007).

17 Oh, J. K., Drumright, R., Siegwart, D. J. \& Matyjaszewski, K. The development of microgels/nanogels for drug delivery applications. Prog. Polym. Sci. 33, 448-477 (2008).

18 Everett, D.H., Basic Principles of Colloid Science, 16-53 (Royal Society of Chemistry, 1988).

19 Bonn, D., Eggers, J., Indekeu, J., Meunier, J., and Rolley, E., Wetting and spreading, Rev. Mod. Phys. 81, 739-805 (2009).

20 Yilgor, E., Eynur, T., Kosak, C., Bilgin, S., Yilgor, I., Malay, O., Menceloglu, Y. \& Wilkes, G. L. Fumed silica filled poly(dimethylsiloxane-urea) segmented copolymers: Preparation and properties. Polymer 52, 4189-4198 (2011).

21 Aida, T., Meijer, E. W. \& Stupp, S. I. Functional supramolecular polymers. Science 335, 813817 (2012).

22 Beijer, F. H., Kooijman, H., Spek, A. L., Sijbesma, R. P.\& Meijer, E. W. Selfcomplementarity achieved through quadruple hydrogen bonding. Angew. Chem. Int. Ed. 37, 75-78 (1998).

23 Kato, T. Self-assembly of phase-segregated liquid crystal structures. Science 295, 2414-2418 (2002).

24 Rudick, J. G. \& Percec, V. Induced helical backbone conformations of self-organizable dendronized polymers. Acc. Chem. Res. 41, 1641-1652 (2008).

25 Okuzono, T., Ozawa, K. y. \& Doi, M. Simple model of skin formation caused by solvent evaporation in polymer solutions. Phys. Rev. Lett. 97, 136103/136101- 136103/136104 (2006).

26 Wang, L., Zhang, Z. \& Ding, Y. Photocrosslinking-induced phase separation in evaporative solvents: formation of skin layers and microspheres. Soft Matter 9, 4455-4463 (2013).

27 Yao, X., Hu, Y., Grinthal, A., Wong, T.-S., Mahadevan, L. \& Aizenberg, J. Adaptive fluidinfused porous films with tunable transparency and wettability. Nat. Mater. 12, 529-534 (2013).

28 Wong, T.-S., Kang, S. H., Tang, S. K. Y., Smythe, E. J., Hatton, B. D., Grinthal, A. \& Aizenberg, J. Bioinspired self-repairing slippery surfaces with pressure-stable omniphobicity. Nature 477, 443-447 (2011). 


$$
S=\nu_{\mathrm{ga}}-\left(\nu_{\mathrm{la}}+\nu_{\mathrm{g}}\right)>0
$$
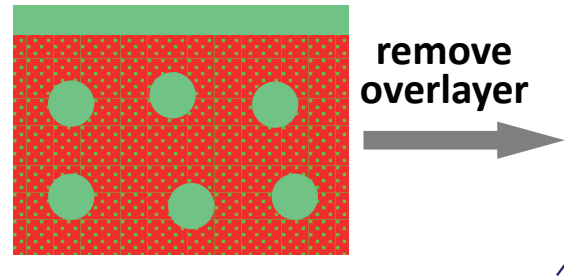

iquid-supramolecular gel

liquid

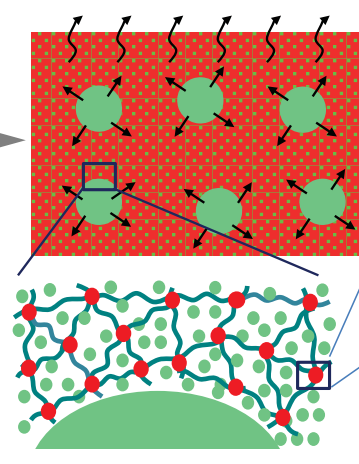

\section{reconfigure}
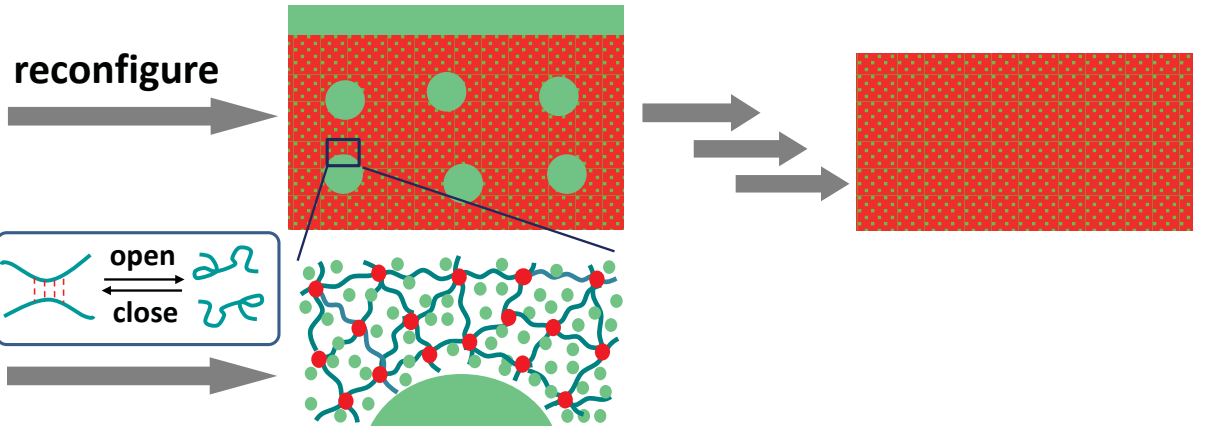


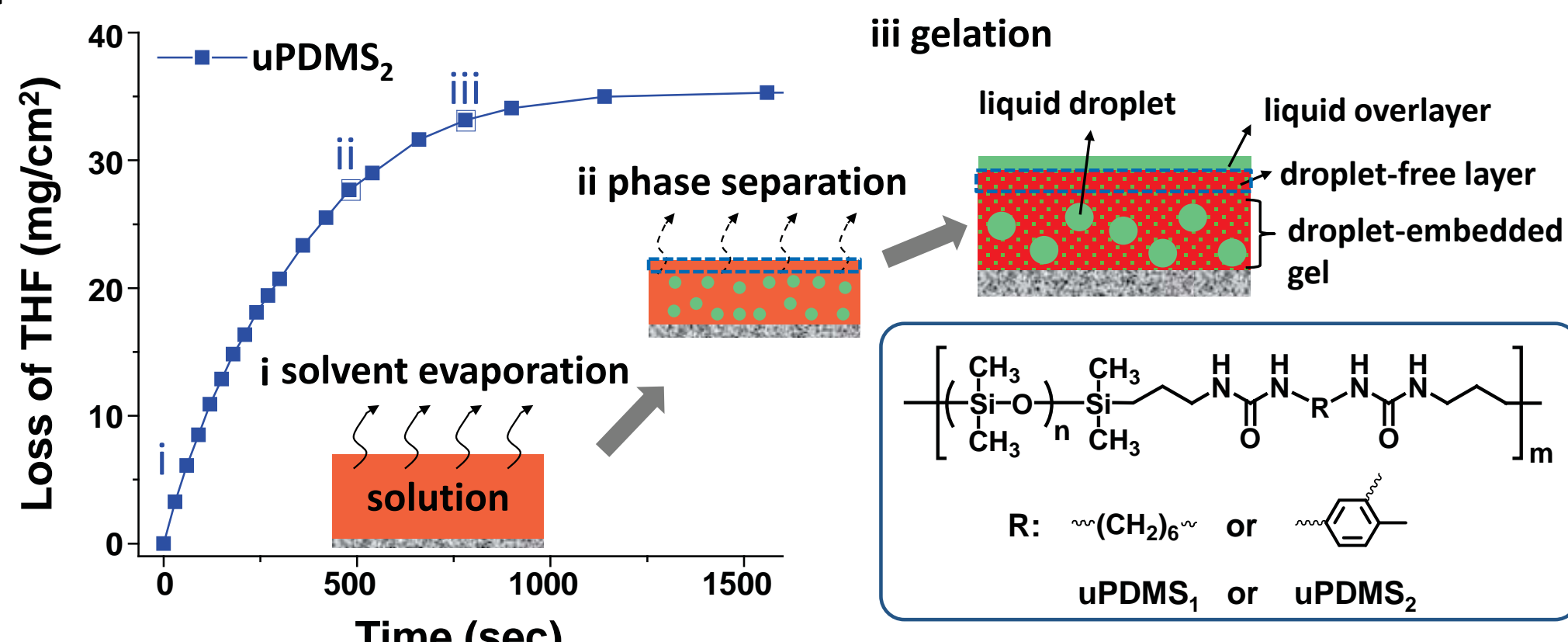

b
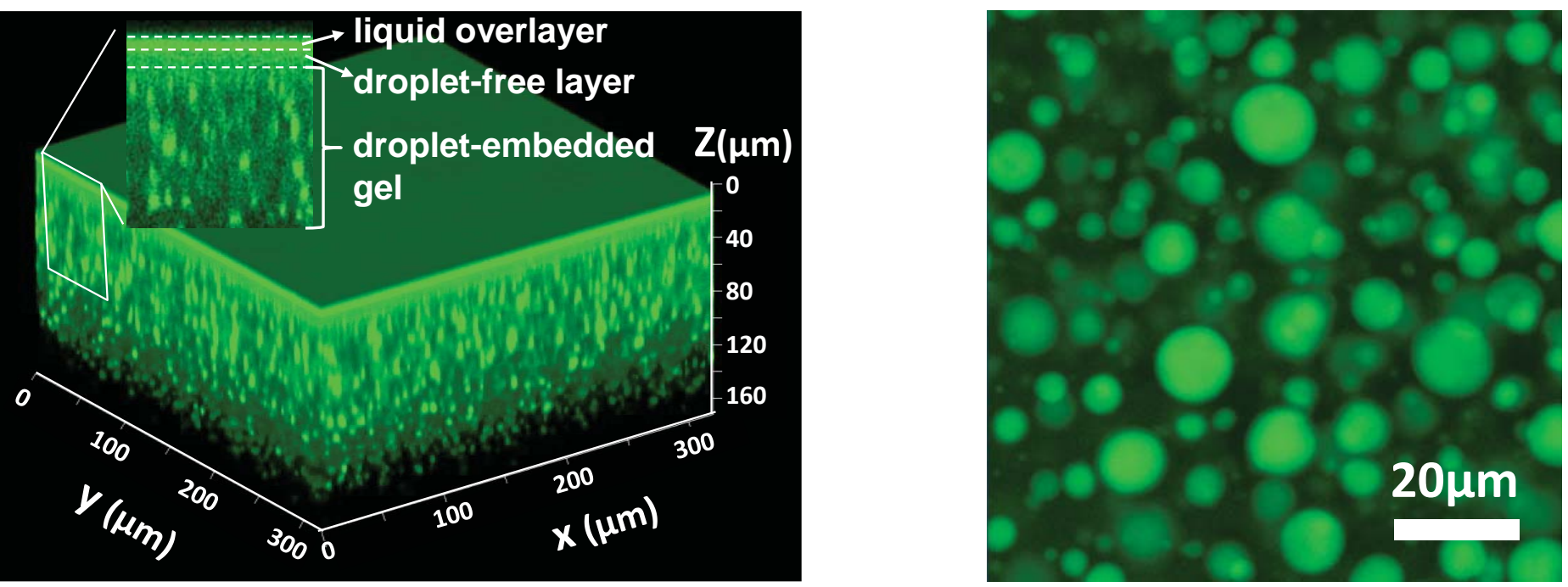

C

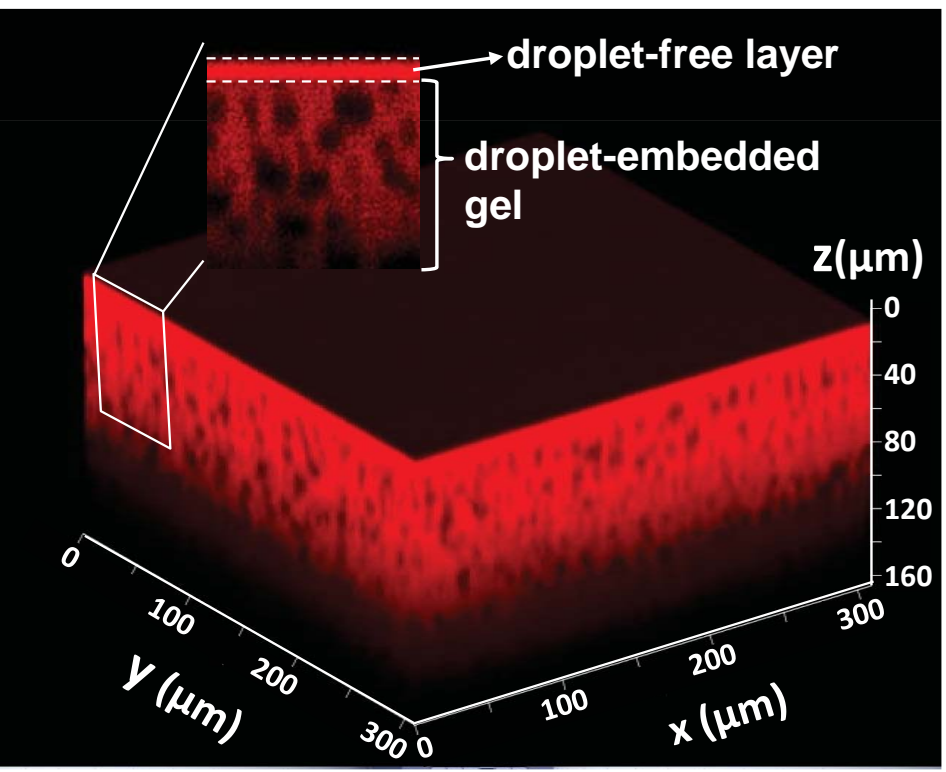

d

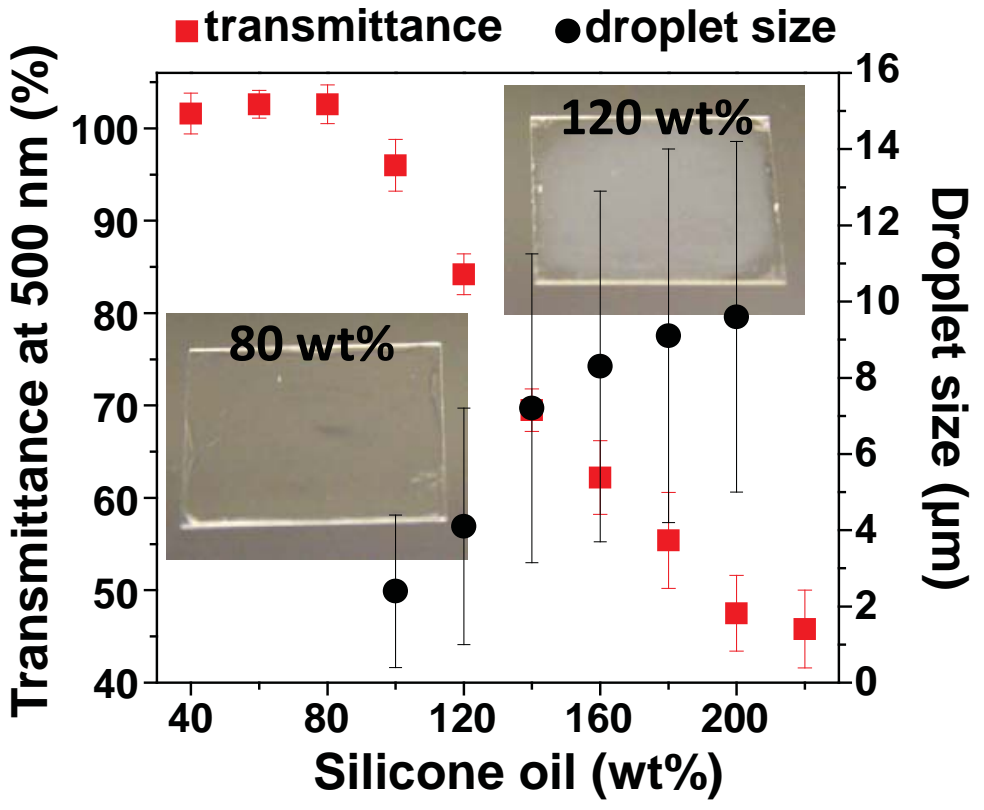


a

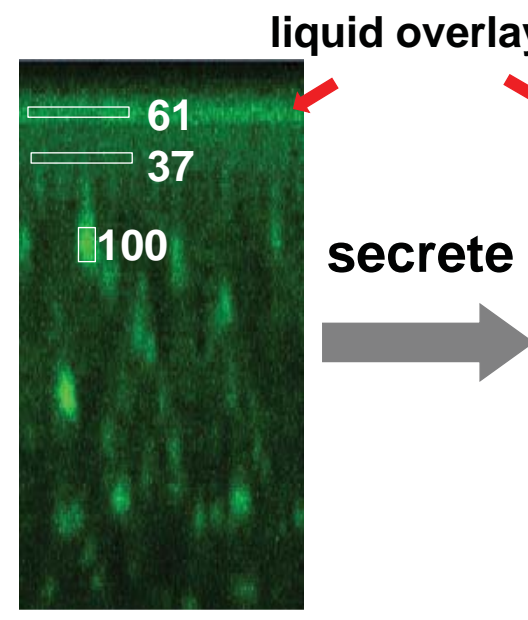

C

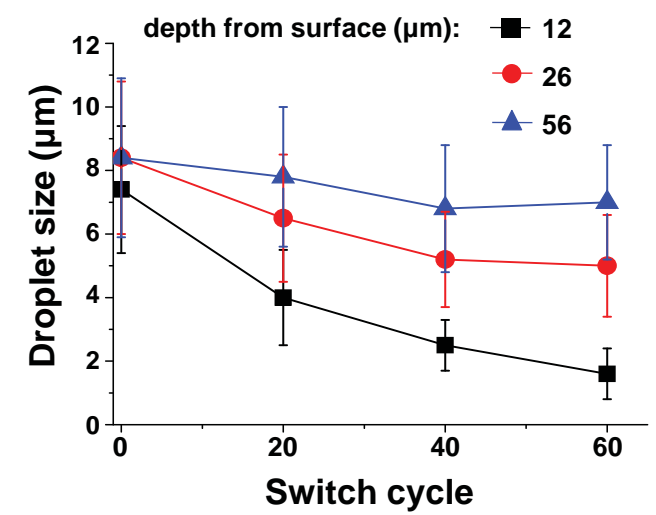

b

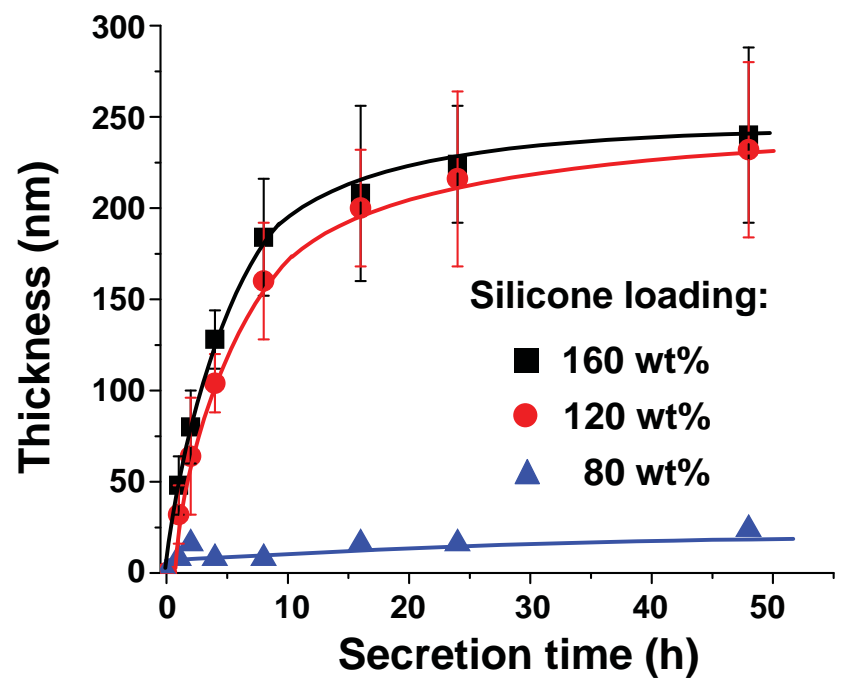

d e

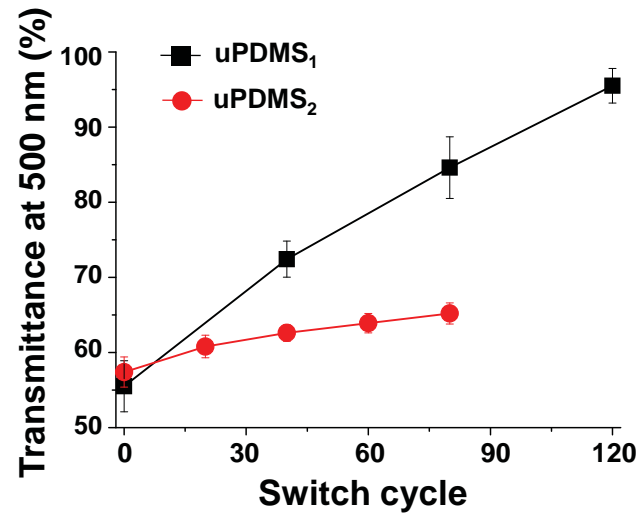


a
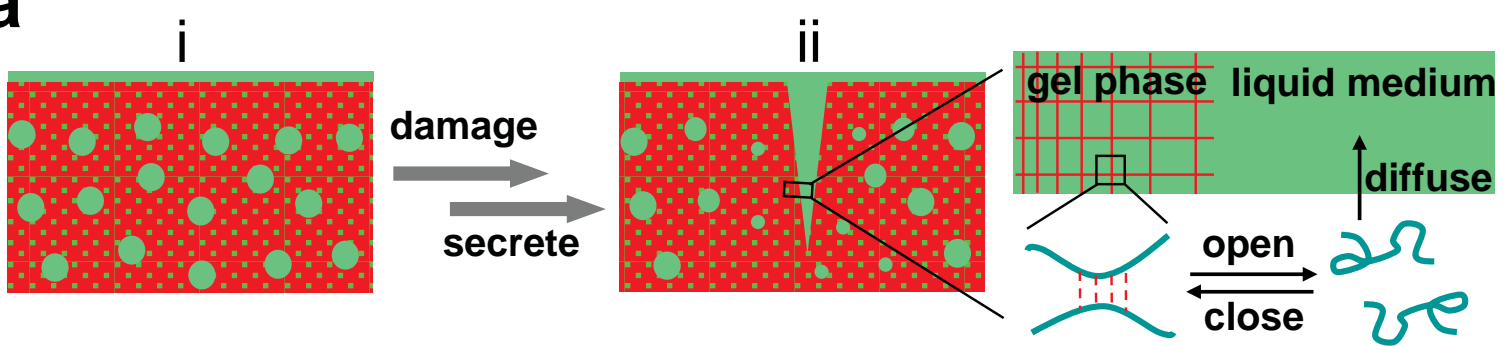

iii

b
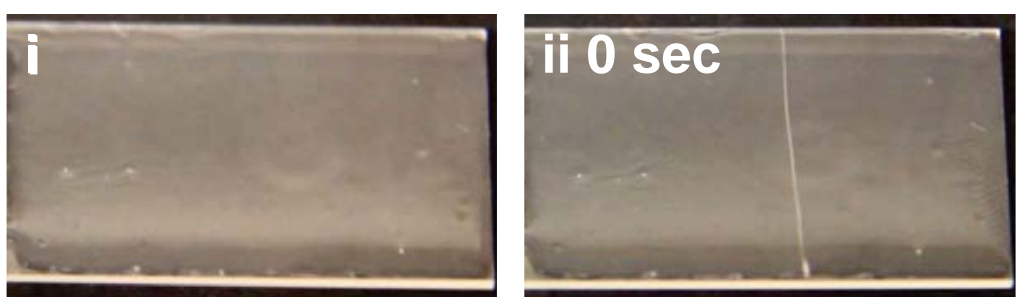
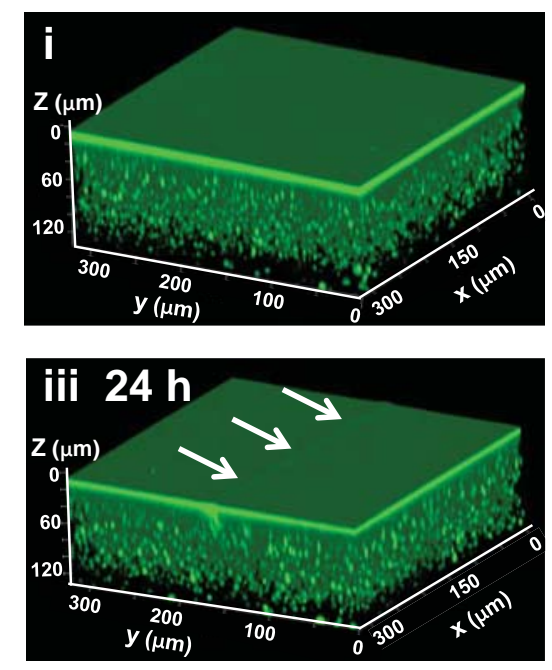
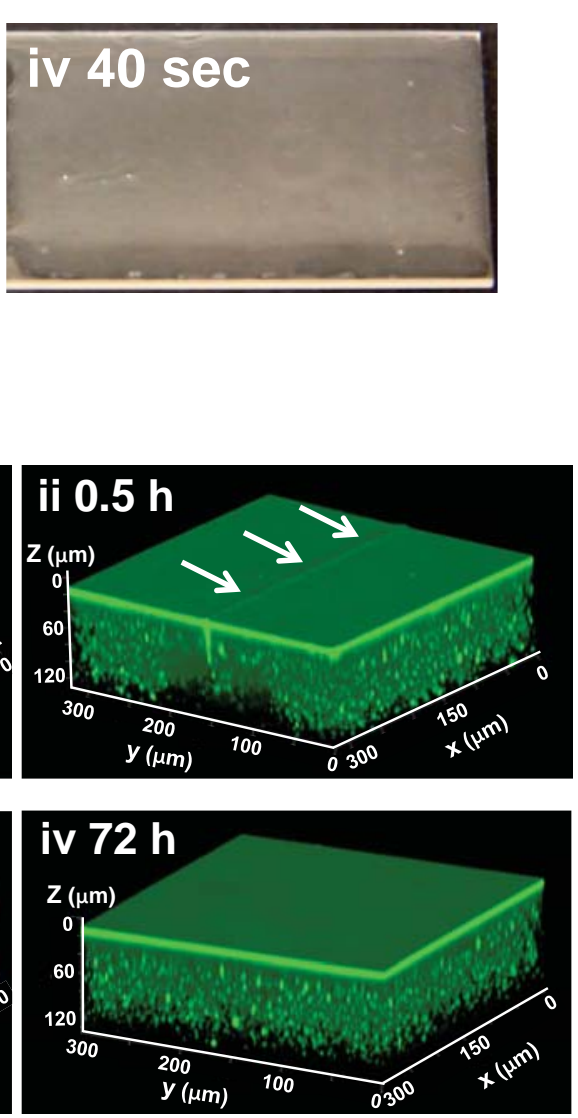

C

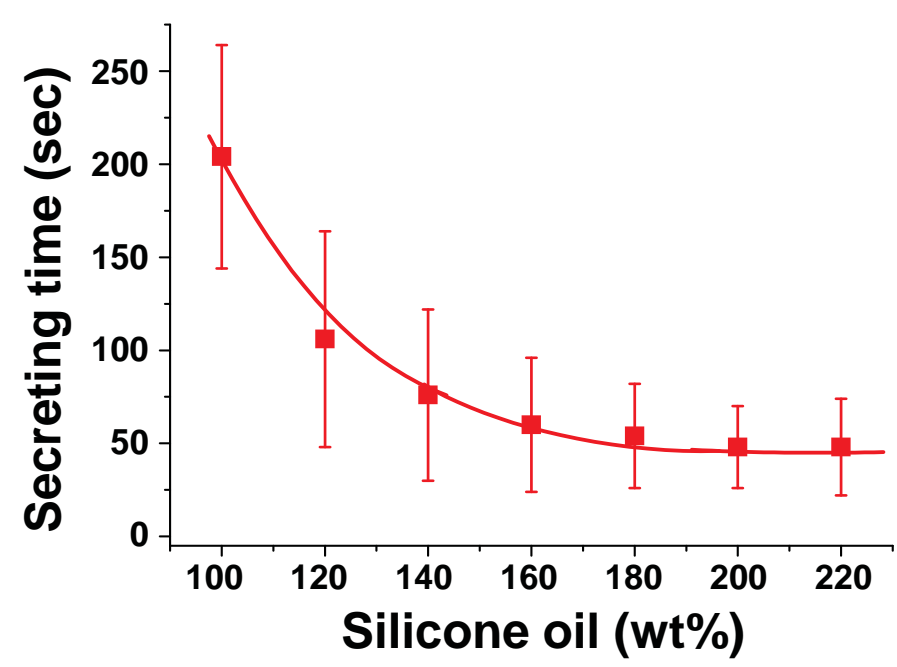

e

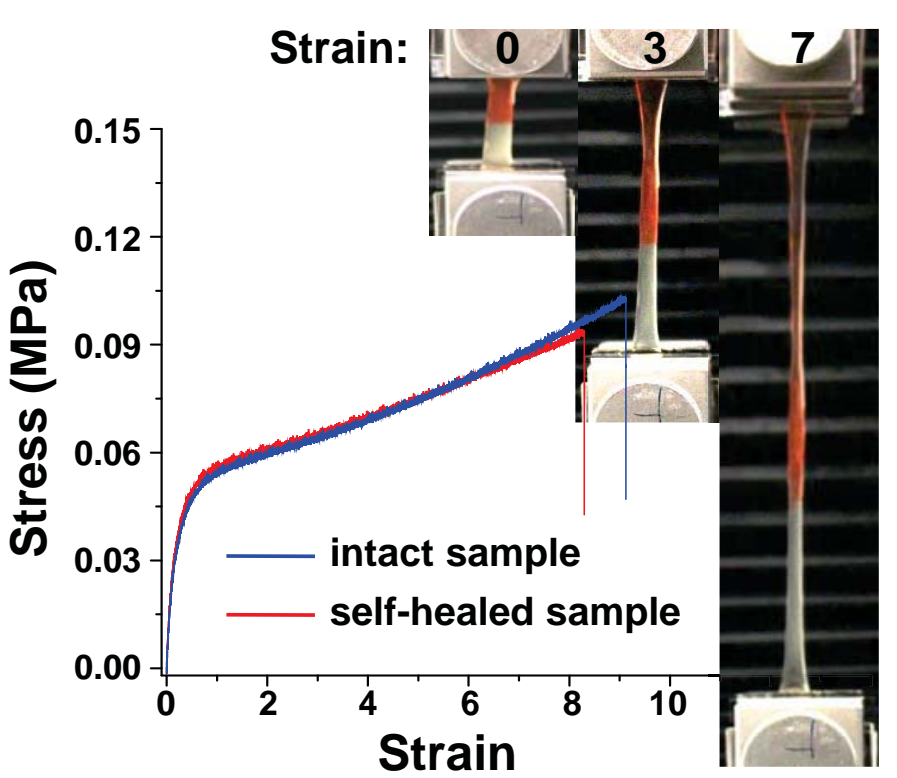


$S=\nu_{\mathrm{ga}}-\left(\nu_{\mathrm{la}}+\nu_{\mathrm{g} \mid}\right)>0$

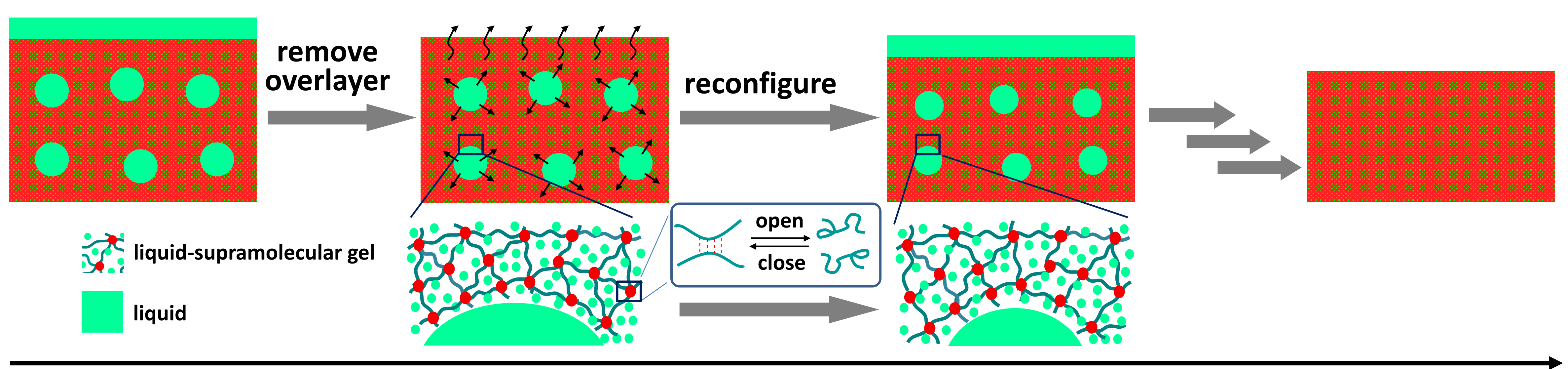




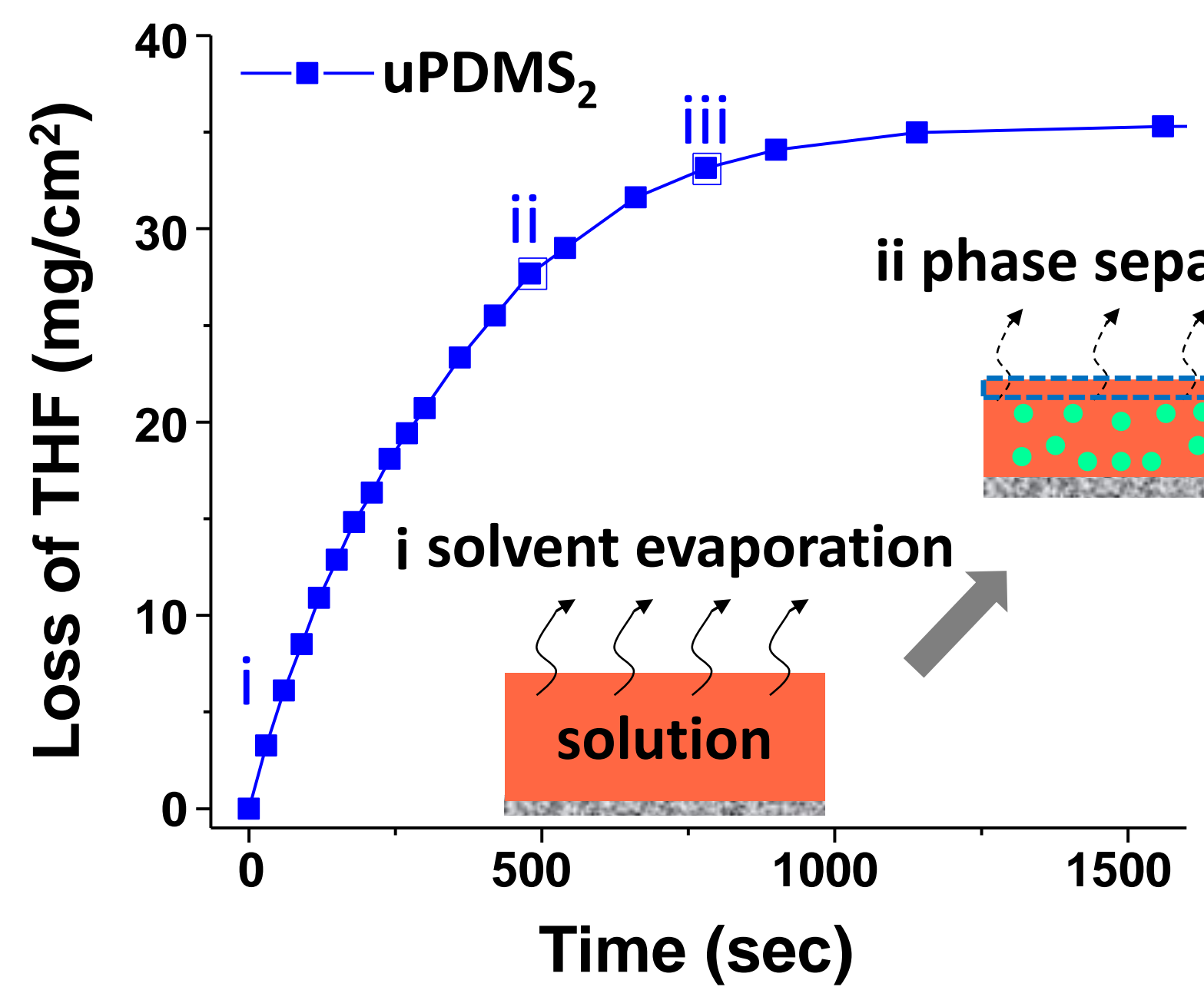

iii gelation

b

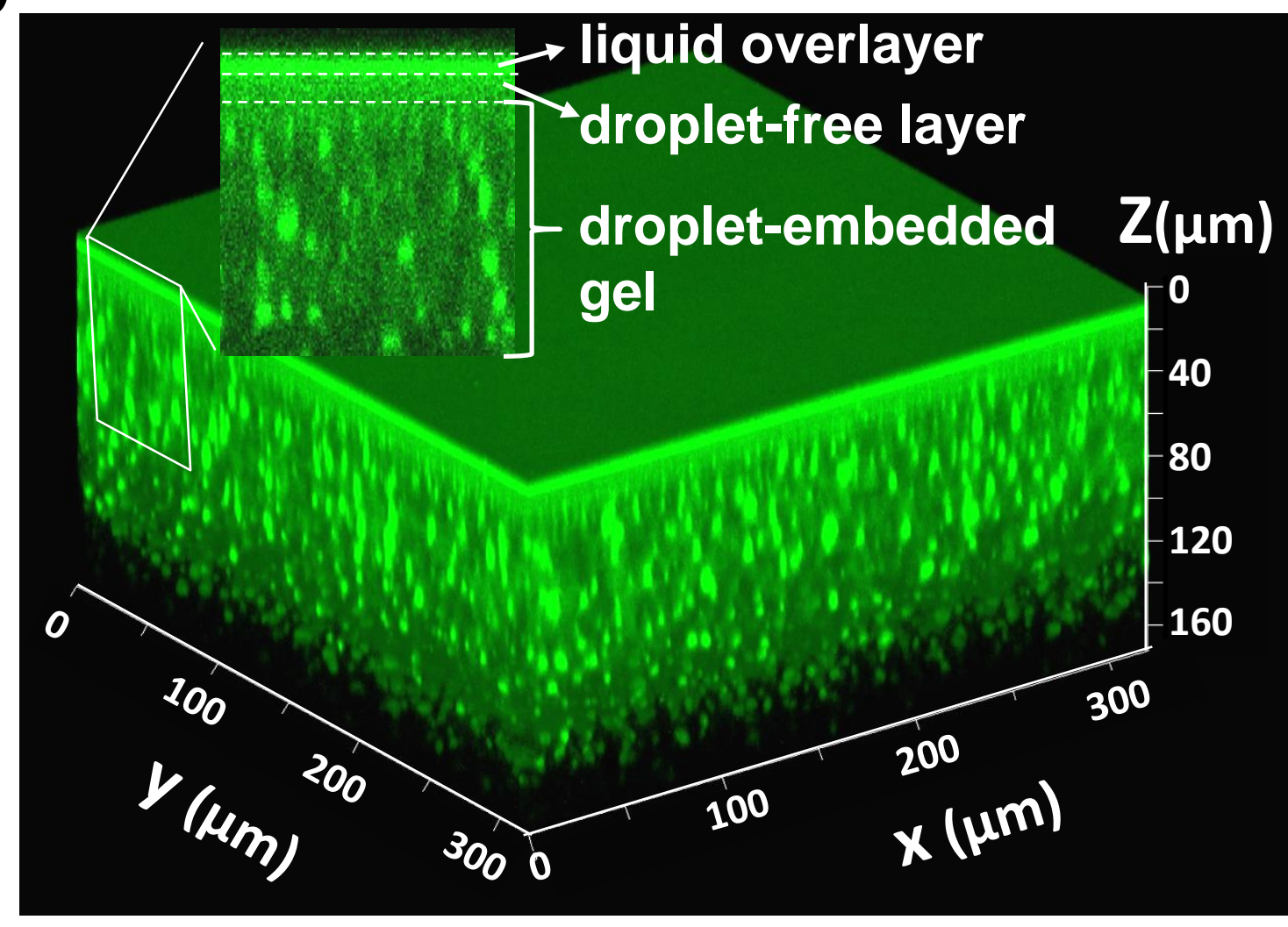

liquid droplet liquid overlayer

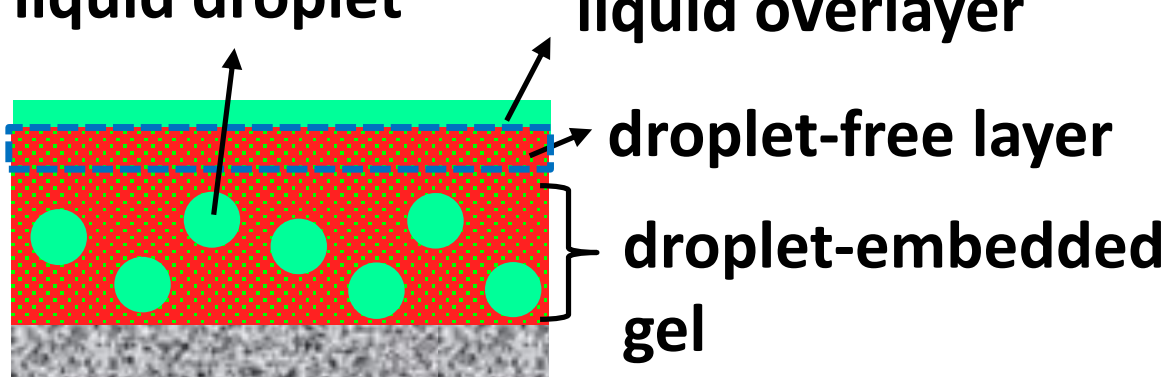

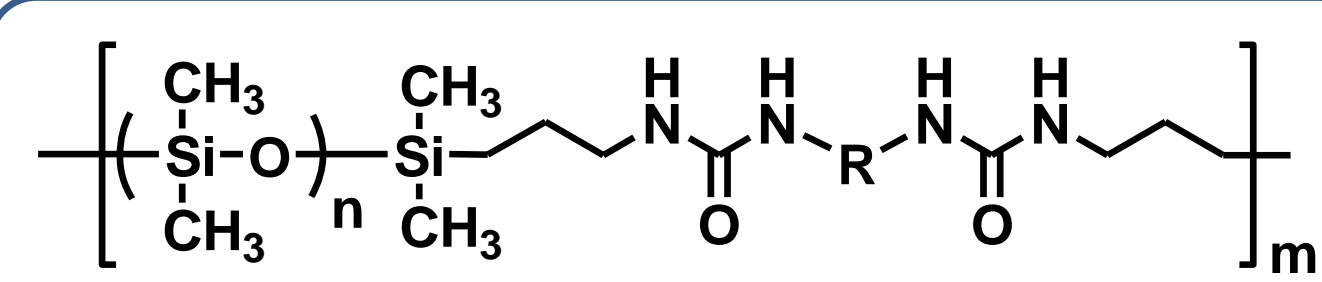

R: $w\left(\mathrm{CH}_{2}\right)_{6} \sim$ or $\cdots$ uPDMS $_{1}$ or uPDMS $_{2}$

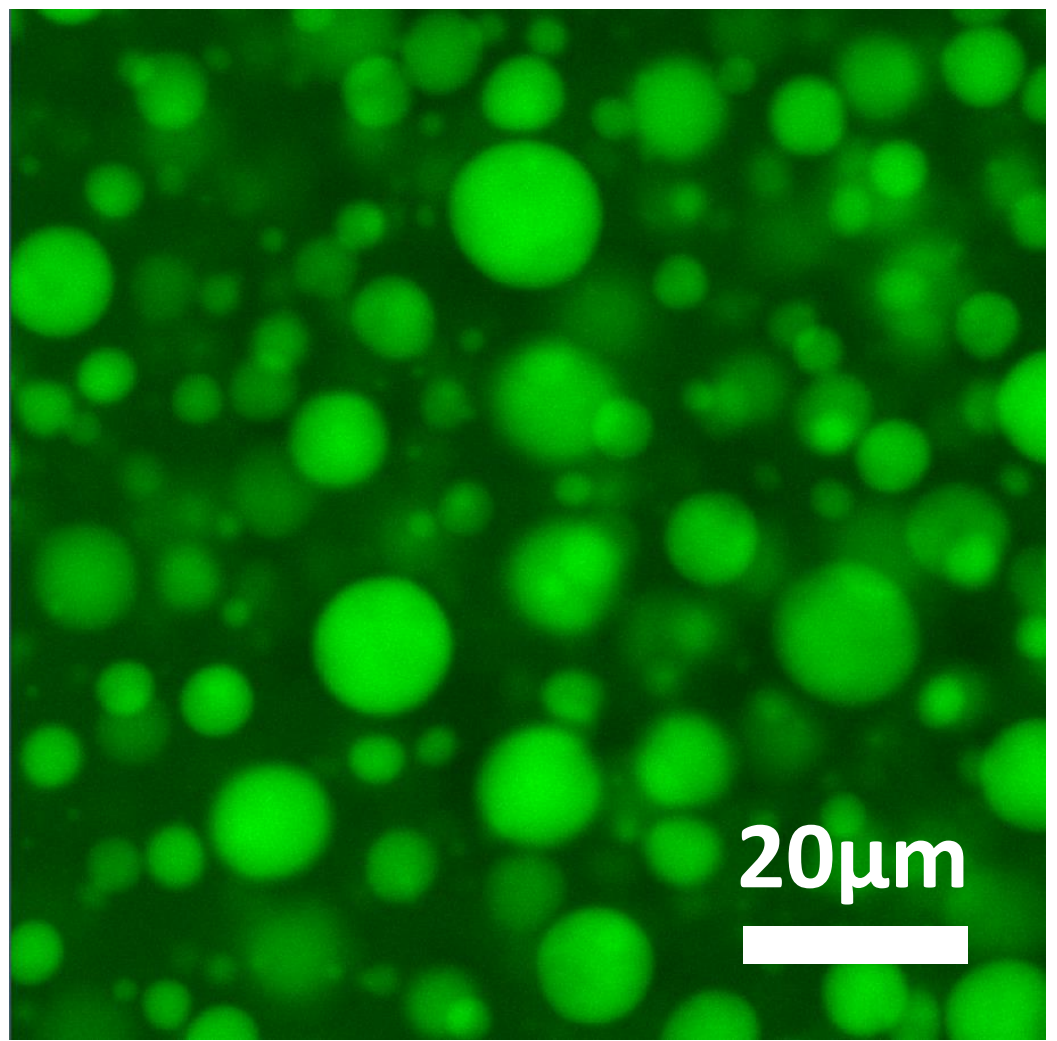

C
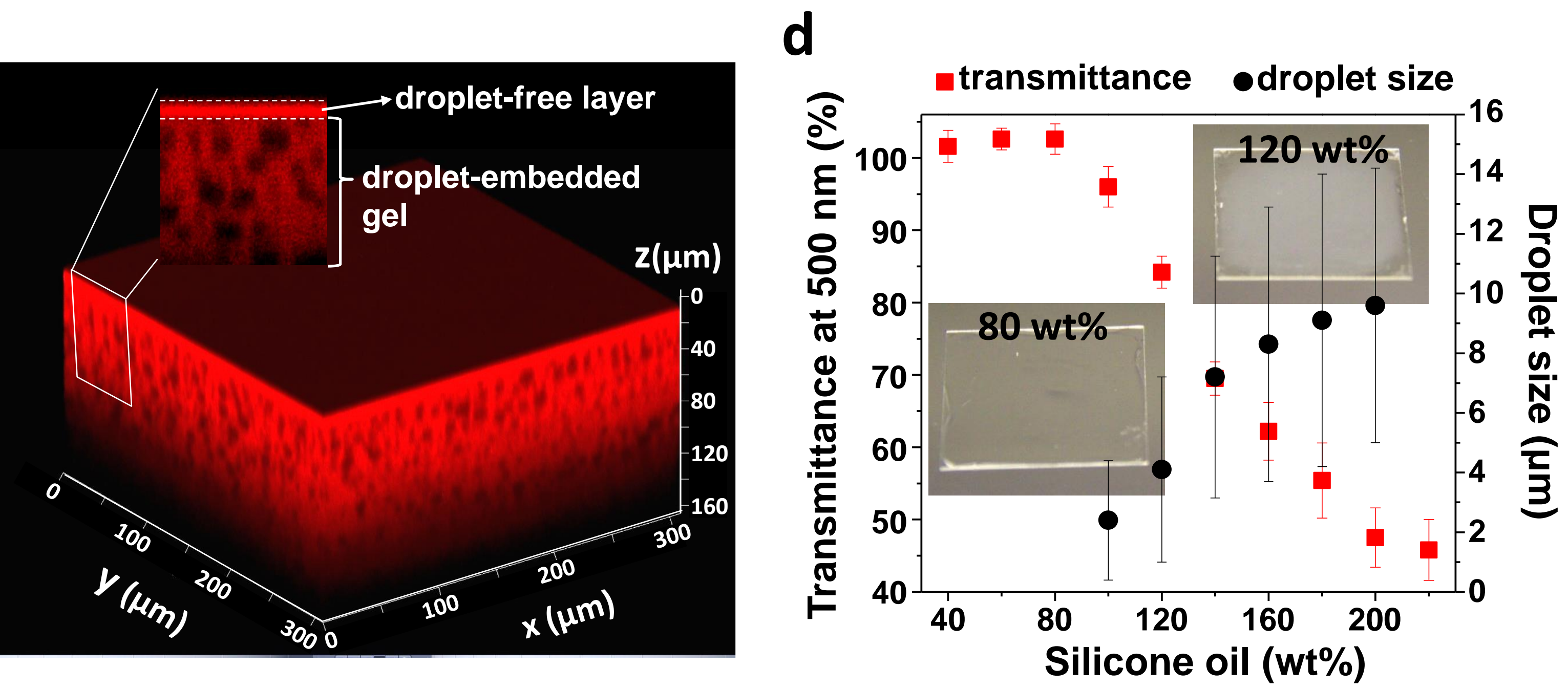

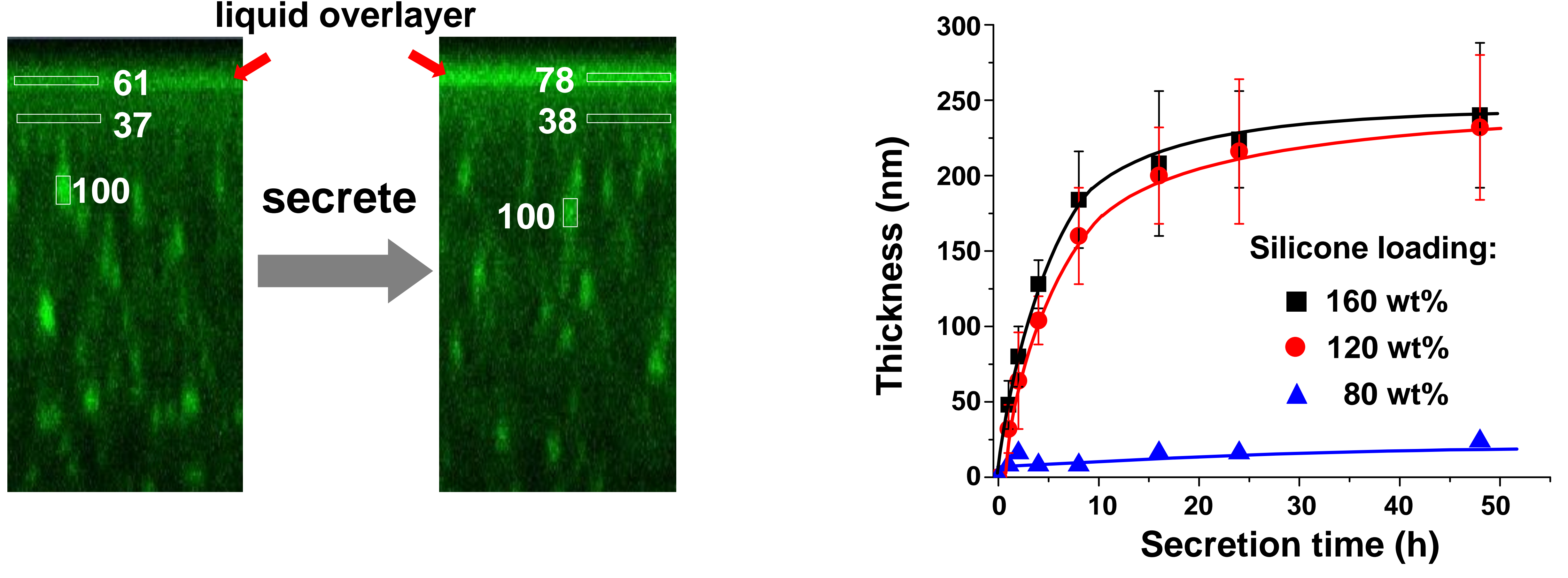

C

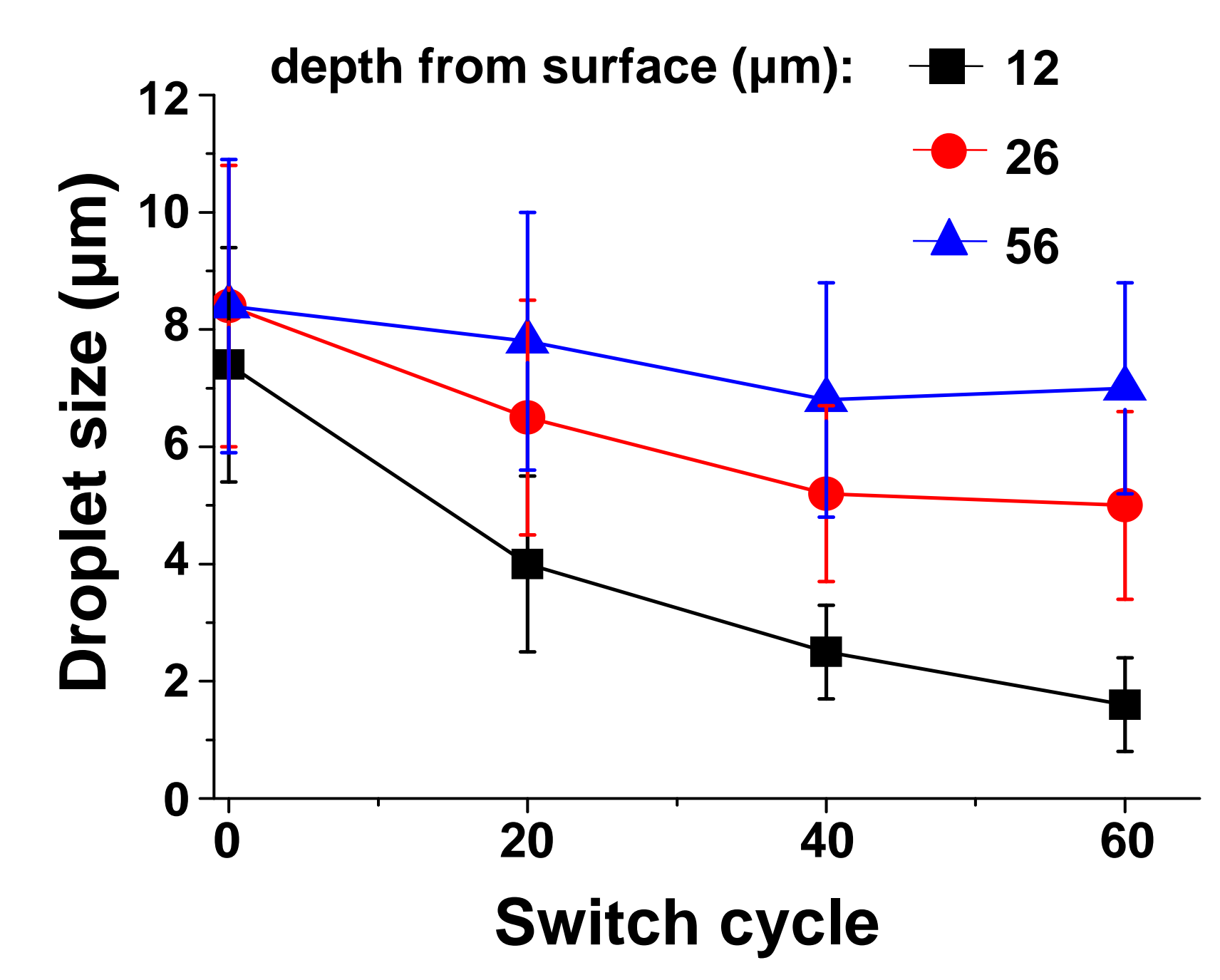

d

e
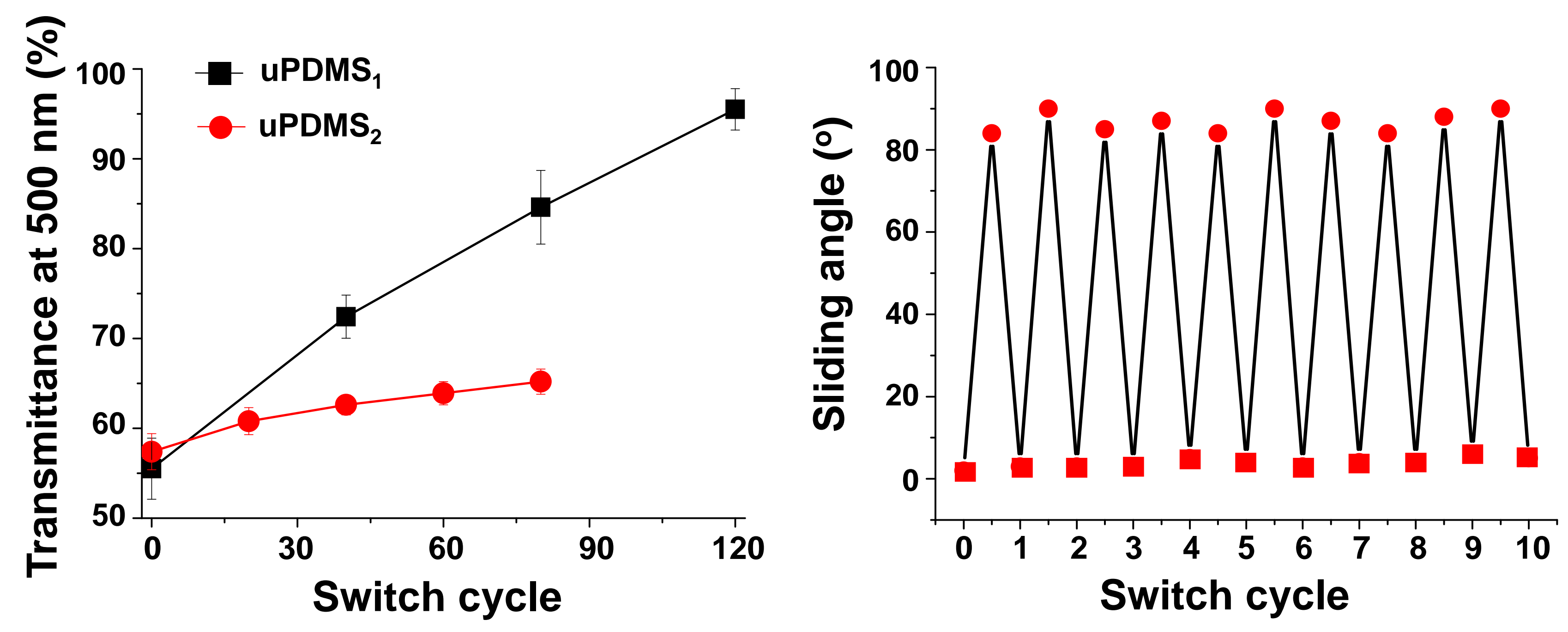
a
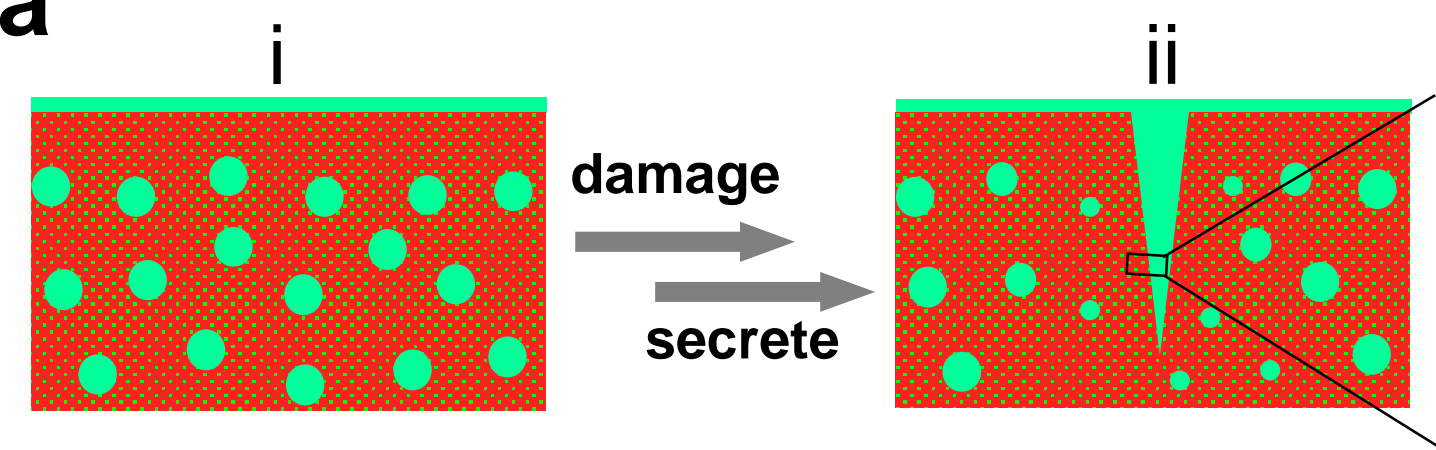

\section{gel phase liquid medium}

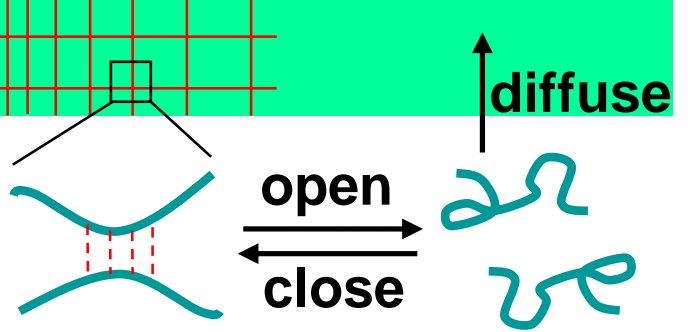

b
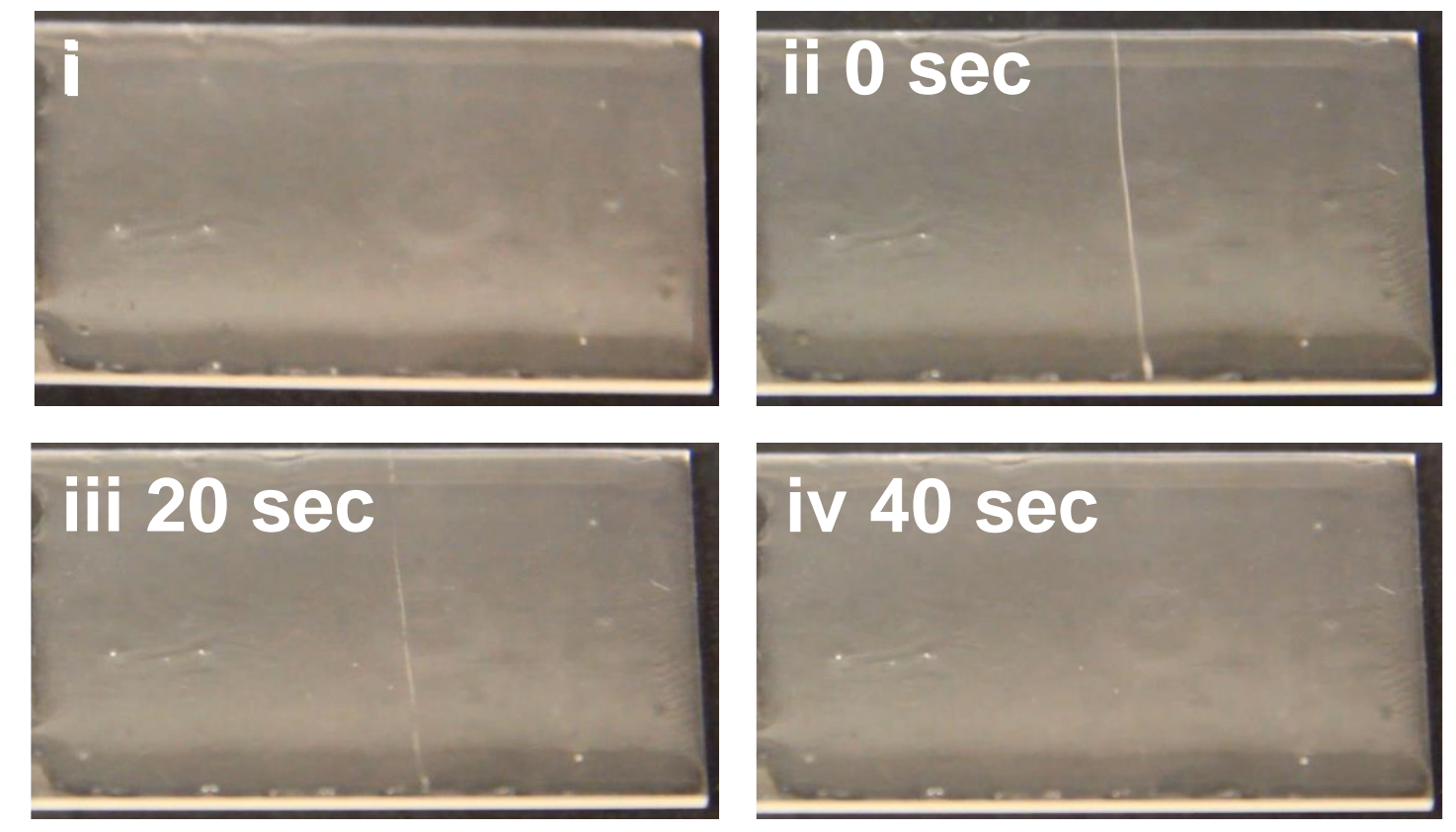

d
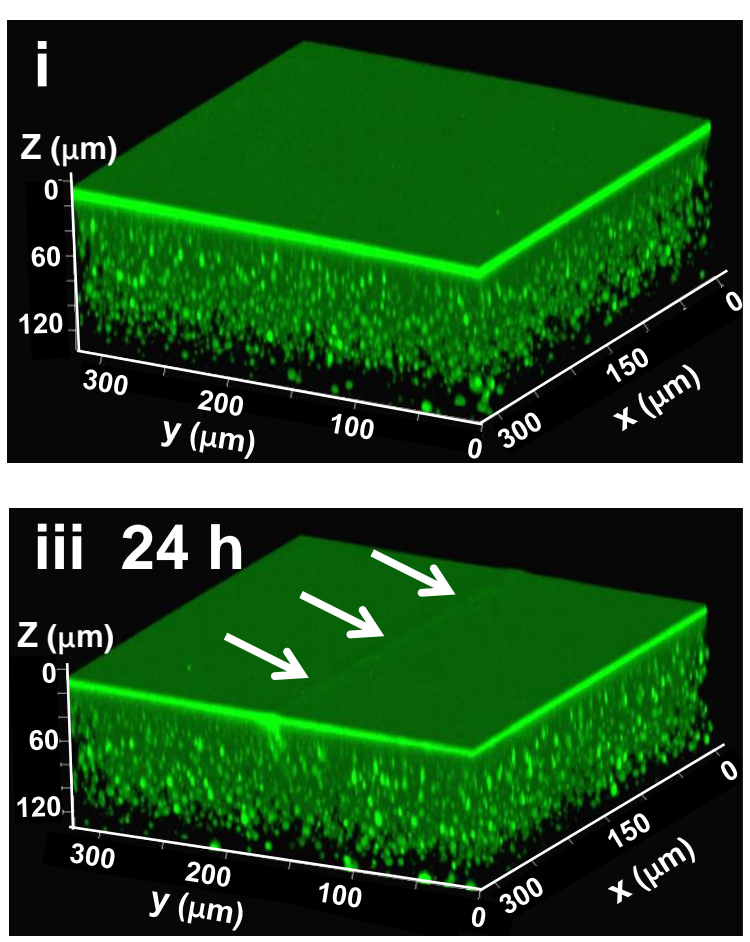

C

e
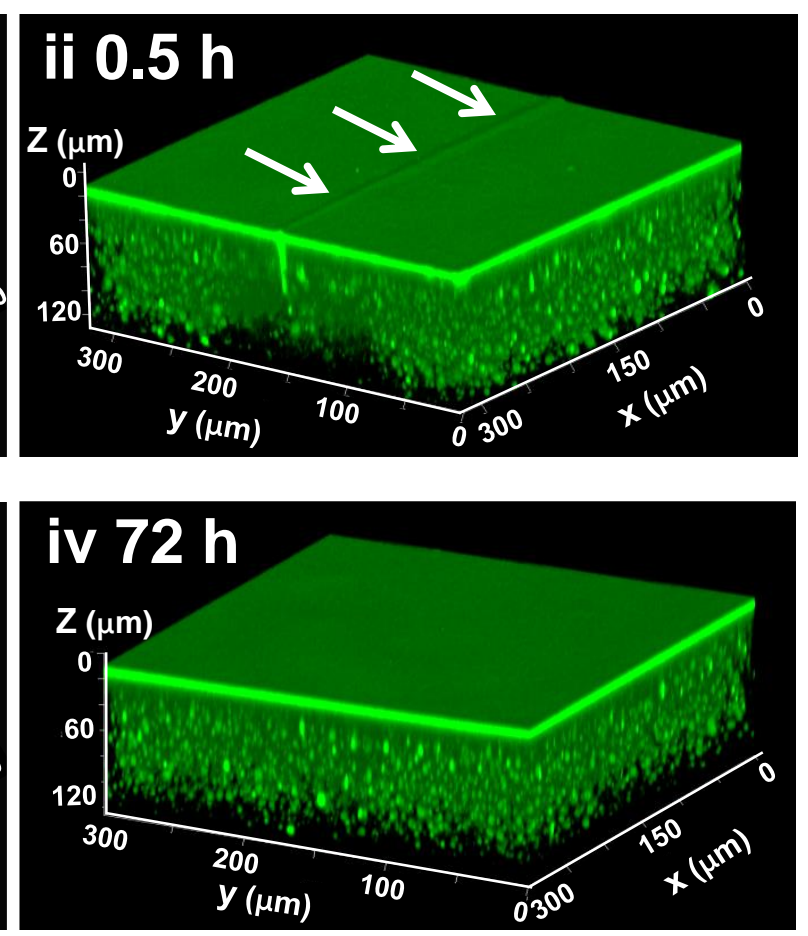

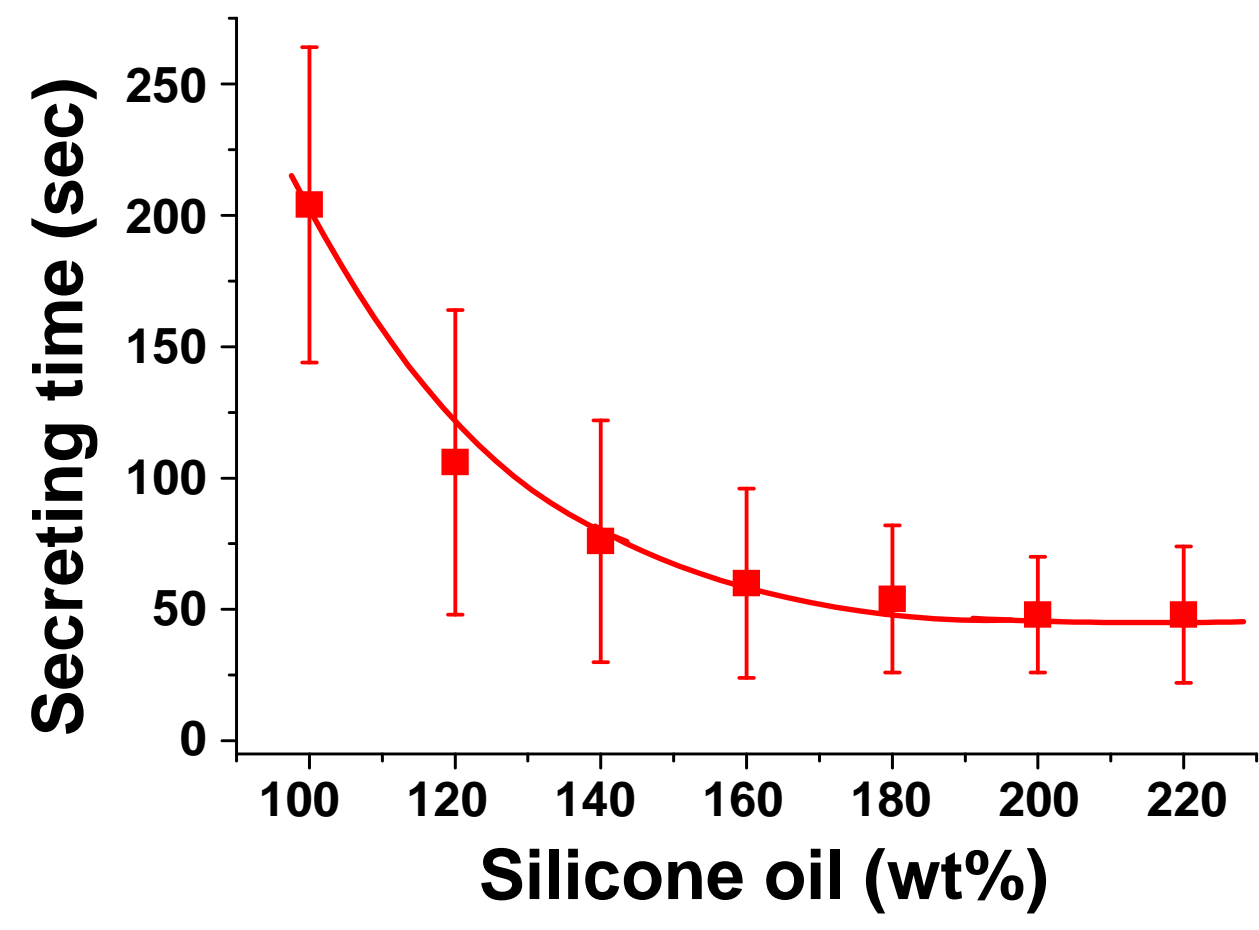

self-heal
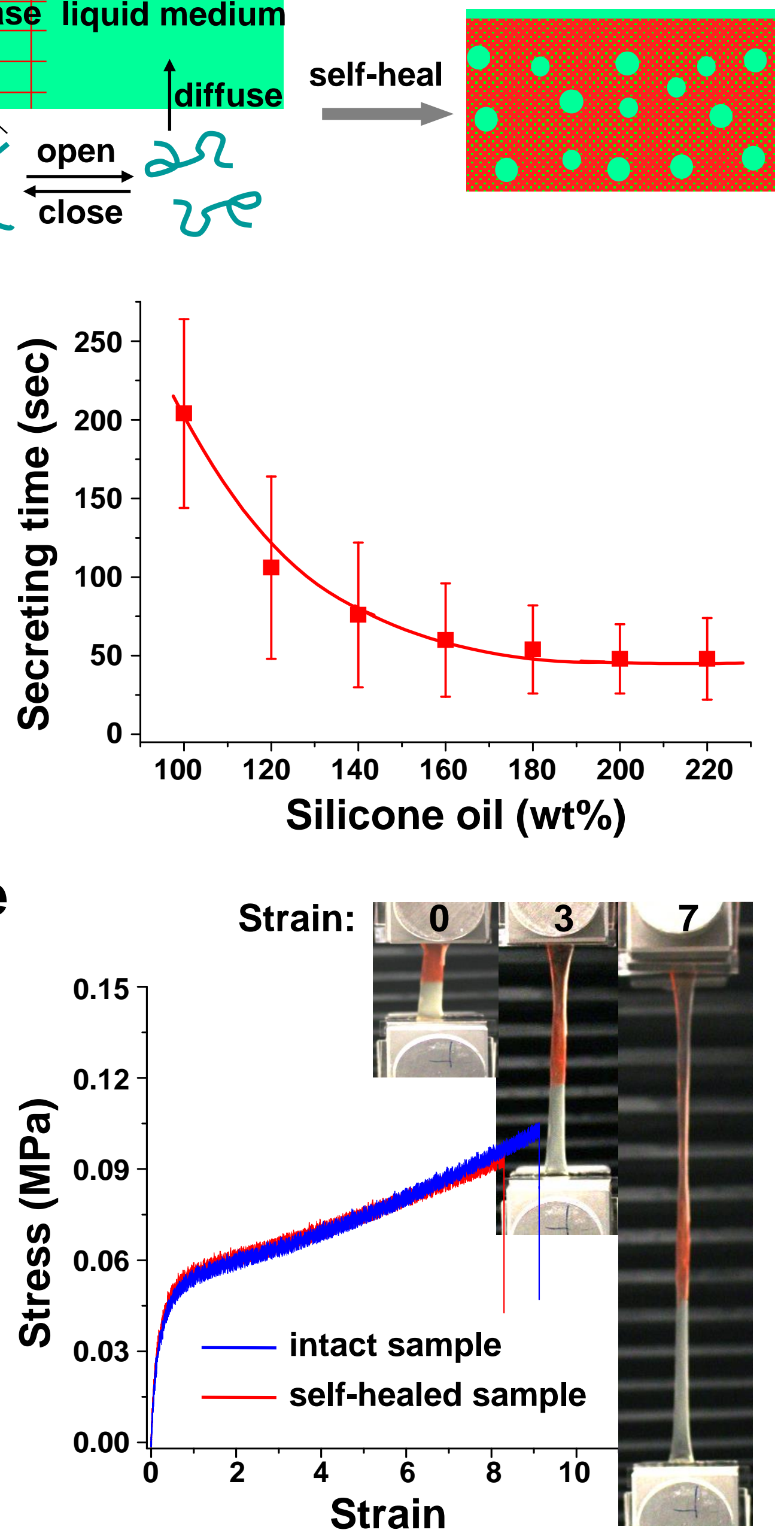